\title{
How 2.5D Maps Design Improve the Wayfinding Performance and Spatial Ability of Map Users
}

\author{
Meng-Cong Zheng * ${ }^{\mathbb{D}}$ and Yi-Wen Hsu \\ Department of Industrial Design, National Taipei University of Technology, 1, Sec. 3, Chung-Hsiao East Road, \\ Taipei 10608, Taiwan; t107588015@ntut.org.tw \\ * Correspondence: zmcdesign@gmail.com; Tel.: +886-2-27712171 (ext. 2827)
}

Citation: Zheng, M.-C.; Hsu, Y.-W. How 2.5D Maps Design Improve the Wayfinding Performance and Spatial Ability of Map Users. Informatics 2021, 8, 88. https://doi.org/10.3390/ informatics 8040088

Academic Editor: Meng Zhang

Received: 10 November 2021 Accepted: 16 December 2021 Published: 19 December 2021

Publisher's Note: MDPI stays neutral with regard to jurisdictional claims in published maps and institutional affiliations.

Copyright: (C) 2021 by the authors Licensee MDPI, Basel, Switzerland. This article is an open access article distributed under the terms and conditions of the Creative Commons Attribution (CC BY) license (https:/ / creativecommons.org/licenses/by/ $4.0 /)$.

\begin{abstract}
Useful information can be provided by 2.5D maps that can take advantage of the additional dimension. However, aside from stereoscopic landmarks, optimal methods for presenting other essential information is unclear. Two experiments were conducted to explore how the presentation of 2.5D maps can effectively increase wayfinding performance. First, analysis was performed to understand the effects of 2.5D maps on wayfinding behavior and map reading. Then, a 2.5D map design was proposed and verified to optimize the 2.5D map presentation of urban environments. The results showed that compared with users of low view angle maps, those using high view angle maps orientated more easily with elements of the map during wayfinding tasks. High view angle maps allowed superior performance, and including transparency and lines improved wayfinding performance. The participants using maps that were opaque and with lines exhibited the most confusion and hesitation. The participants who used maps that were transparent and had lines exhibited the least confusion and hesitation. Highlighting buildings at intersections can help map users use the intersections as references and increase their intuitive spatial ability.
\end{abstract}

Keywords: 2.5D map; wayfinding; view angle; spatial ability; information visualization

\section{Introduction}

Maps are crucial media used by individuals to familiarize themselves with a space. When a map corresponds with the actual environment, the map can generate spatial knowledge and ensure successful wayfinding. Survey knowledge is achieved by individuals through mentally visualizing map-like representation of the environment [1,2]. However, modern cities have complicated environments, where the use of conventional two-dimensional (2D) maps for environmental cognition and wayfinding is challenging. Previous studies have investigated the influence of different factors such as spatial cognition and engineering information format on construction workers' performance and found that three-dimensional (3D) information affected their work positively [3-7]. Sweany [4] measured the cognitive demands of three types of information: 2D plan sets, 3D computeraided design (CAD), and 3D printed models on construction workers. Statistical analyses proved that subjects of both low and high spatial cognition performed best with 3D physical models. The view angle of 3D maps differs from that of the human eye. Therefore, errors may occur during the acquisition of information from an environment after reading maps. The wayfinding task revealed that most erroneous decisions arose from participants' overestimation of the environmental information they obtained. Although 3D maps can show a full view of spaces, the results showed that areas on 3D maps often overlap. Consequently, the participants were unable to recognize the spatial relationship between floors, and thus struggled with judging the location of stairs.

Maps are crucial media used by individuals to familiarize themselves with a space. When a map corresponds with the actual environment, the map can generate spatial knowledge and ensure successful wayfinding. Survey knowledge is achieved by individuals through mentally visualizing map-like representation of the environment $[1,2]$. The map is 
often held basically to be a means of communication [3]; the map-maker is attempting to communicate information to the map-user [4]. Maceachren [5] proposed that, when our vision is processing a map, we first start from those marginal or discontinuous regions on the map and then undertake a visual description and arrangement in terms of size, depth, and brightness among different symbols. Secondly, on a higher level, we will evaluate what we have acquired in the previous steps. At this moment under the knowledge schema, the visual description then transmits, questions, and adjusts with knowledge in long-term memory, deriving certain meaning from maps. That is, via the visual cognition, information is being recreated, and redefined again and once more. Therefore, a model is continually developed through the processes of reading, understanding, and modifying maps into actions.

Among all wayfinding behaviors, landmark navigation is the tool most commonly used to guide direction. Landmarks play a critical role in daily spatial tasks for wayfinding and navigation [6-8]. In addition, "good" landmarks [9], i.e., visually prominent and familiar objects, may have recognizable logos and are located on the pedestrians' route. A landmark is eye-catching not only because of its own characteristics, but also its ability to be distinguished from similar objects in the environment [10]. Landmarks are crucial reference information when people are deciding the route direction [11]. Landmarks provide essential information at an intersection where direction change is required to continue the route, and help to create a visual model of key parts of the environment [12-14]. Golledge [15] argued that a landmark has two functions. First, it plays the role of an anchor, namely serving as a point that connects different regions in an environment. Second, it is used as an auxiliary tool for wayfinding, and wayfinders can use landmarks as a point of reference for direction identification and route decision. Successful spatial positioning occurs when a person's brain can form an environmental cognition map to determine his or her location [14]. Once this information is available, the shortest and most efficient route from his or her current location to the desired destination can be quickly identified [16,17]. Ito and Sato [18] stated that relative to referral information, such as "continue walking for another two blocks" and "at the second traffic light," information that described building types (e.g., a soccer field) enabled wayfinders to be more certain of their directions in the wayfinding process.

Koláčný [19] indicated the process from map-maker's encoding to map-user's decoding. Map makers take the trouble of translating geographic reality into cartographic symbols, because maps are the most effective and efficient way of transferring data to users and of providing insight into, and an overview of, these data [20]. Map-reading studies have shown that after users read a map, they construct a cognitive map; however, differences exist between users' perceived image and that of the map makers [3,19], and such differences must be investigated. Orientation is a type of behavior employed to solve spatial problems. Wayfinding decisions involve map users matching the actual environment with their perceived map.

Fujimori et al. [21] shows cartographers also make use of points, lines, and areas to illustrate the spatial relationships. These spatial relationships are divided into four types: Connectivity, Near, Intersection, and Containment. Hence, cartographers make use of these symbols to display objects in the real world and further show the spatial relation between these objects by reflecting the relation within these symbols on the map. Cartographers describe the 3D space on a 2D map by "symbols". Generally speaking, cartographers make use of visual variables, which include size, hue(color), value, texture, orientation, and shape to show the difference among symbols [22]. Landmarks usually act as anchor points for organizing other spatial information into a layout. Landmarks also act as organizing features in a wayfinding context [15]. Judging from landmark-checking, we can know where we need to turn. Landmark-checking also helps us identify where we are and whether we are on-route or not. People rely on a variety of architectural cues to find their way through buildings. These architectural features form a system of landmarks [7] and should, therefore, be included in the list of items that need to be considered when 
encoding diagrams [23]. Ottosson [4] observed that experiments featuring map-reading and wayfinding required real in-depth investigations.

However, modern cities have complicated environments, where the use of conventional two-dimensional (2D) maps for environmental cognition and wayfinding is challenging. Previous studies have investigated the influence of different factors such as spatial cognition and engineering information format on construction workers' performance and found that three-dimensional (3D) information affected their work positively [24-28]. Sweany [25] measured the cognitive demands of three types of information: 2D plan sets, $3 \mathrm{D}$ computer-aided design (CAD), and 3D printed models on construction workers. Statistical analyses proved that subjects of both low and high spatial cognition performed best with 3D physical models. The view angle of 3D maps differs from that of the human eye. Therefore, errors may occur during the acquisition of information from an environment after reading maps. The wayfinding task revealed that most erroneous decisions arose from participants' overestimation of the environmental information they obtained. Although 3D maps can show a full view of spaces, the results showed that areas on 3D maps often overlap. Consequently, the participants were unable to recognize the spatial relationship between floors, and thus struggled with judging the location of stairs. Only the successful matching of maps with the actual environment can enable successful wayfinding and create useful spatial knowledge [29].

Without proper navigation, map users using street view images with 3D view angles still become lost. Passini [30] believed that wayfinding maps should provide information confirming a path and increasing understanding of a space. Passini also proposed using different view angles in the presentation of wayfinding maps. View angle refers to the angle at which geographical features are projected on a planimetric map. Most maps have a top view angle, whereas some use a perspective view angle to create a sense of space. You et al. indicated that the view angle can be changed for the entire map or for specific landmarks; the same geographical features can be presented differently. Conventional top view angles are easy for map users to read and can help them form spatial structures and generate cognitive maps. However, when map users use such maps in wayfinding tasks, they can encounter problems transforming the 2D spaces of the map into the actual $3 \mathrm{D}$ spaces [31]. Visual perceptions are expressed in one of three methods, namely 2D, 2.5D, or 3D [32]. The differences between the methods are as follows: the $2 \mathrm{D}$ method shows only one facet, the 3D method shows all facets, and the 2.5D method combines $2 \mathrm{D}$ and 3D graphic technologies. By defining the map user as the origin of the map's coordinate system, the 2.5D method employs perspective drawing techniques to present direction and depth on the map. Perspective increases the dimensions of a map and enriches its features, as well as helping users form spatial structures and cognitive maps. In a study by Kealy [33], map users who used perspective maps recalled significantly more environmental features and were better able to locate a feature when they mentally reconstructed the map. Because self-localization and spatial orientation are essential to wayfinding [34], perspective drawing was used in the current study to design 2.5D maps, in which the depth axis is the only vanishing point. The design allows users to have first-person perceptions. Visual perception transforms the perceived environment into 3D space. Therefore, compared with 2D maps, 2.5D maps can facilitate cognition because they include 3D stereoscopic landmarks. The map content is always "tilted." Limberger et al. [35] indicated that the effectiveness of a view angle for a perspective map is determined by the complexity of its inner nodes and distribution of height values. The view angle can range from $0^{\circ}$ to $90^{\circ}$, although an angle between $30^{\circ}$ and $60^{\circ}$ is more reasonable. The shadow of an object on a map can provide additional hints to users. Perspective maps can improve space and landmark recognition, thus, these maps are superior to 2D maps [36]. However, Liao et al. discovered that perspective map users did not perform as well as 2D map users because of excessive map information and view obstruction [37]. The 2.5D maps can take advantage of the additional dimension and provide useful information. However, aside from stereoscopic landmarks, optimal methods for presenting other essential information 
is unclear. Two experiments were conducted to explore how the presentation of 2.5D maps can effectively increase wayfinding performance. First, analysis was performed to understand the effects of 2.5D maps on wayfinding behavior and map reading. Then, a $2.5 \mathrm{D}$ map design was proposed and verified to optimize the 2.5D map presentation of urban environments.

\section{Materials and Methods}

\subsection{Experiment One: View Angle and Density of Current 2.5D Maps}

The keyword "map" in both Chinese and English was used to find mobile map applications that provide 2.5D map functions using iOS or Android systems. The selected applications were among the ten most popular digital map applications. Five mobile map applications were selected, namely Google maps, Apple maps, maps.me, Baidu map, and AutoNavi map. Most 2.5D maps are perspective maps that allow users to adjust the view angle. These maps have two common elements: protruding stereoscopic buildings and adjustable view angles. The first experiment was based on building density. Xia et al. [38] defined building density as the total area of all buildings divided by the site area of the planning region. The presentation of buildings can be high- or low-density. In the experiment, a density level of $50 \%$ was the median value, and a density $>50 \%$ or $<50 \%$ was classified as high $(\mathrm{H})$ or low $(\mathrm{L})$, respectively. We built a 3D model of the actual area of downtown Taipei, including roads and buildings, and made experimental samples based on various angles and densities. In this study, most of the buildings on our map of Taipei City's Daan District are tall. We want to use Taipei City as a base to reduce the effect of height differences in the area. In terms of the angle for viewing the sample, the center of the bottom of the model was used as the axis of rotation, and viewers began viewing from a vertical angle (top view) of $90^{\circ}$ before moving horizontally to $0^{\circ}$. Three view angles were chosen for the experiment, namely $90^{\circ}, 60^{\circ}$, and $30^{\circ}$. The different view angles and building densities formed six combinations, namely $\mathrm{H}^{\circ} 0^{\circ}, \mathrm{H}_{6} 0^{\circ}, \mathrm{H} 30^{\circ}, \mathrm{L}^{\circ}, \mathrm{L}^{\circ}$, and $\mathrm{L} 30^{\circ}$. Limberger et al. proposed that a view angle between $30^{\circ}$ and $60^{\circ}$ is reasonable. The $90^{\circ}$ view angle was included because it represents a $2 \mathrm{D}$ planimetric map with $3 \mathrm{D}$ buildings. The maps were grey with colored mission markers. In all, 36 people participated, were 20-30 years old, half male and half female. Since we drew the map in the experiment based on the actual appearance of Da-an district in Taipei, we invited people who had never moved to this area to be the participants. The participants were divided into six groups at random, each group with three male and three female participants. All groups used the same type of map with the same view angle and density. Maps are shown in Figure 1.

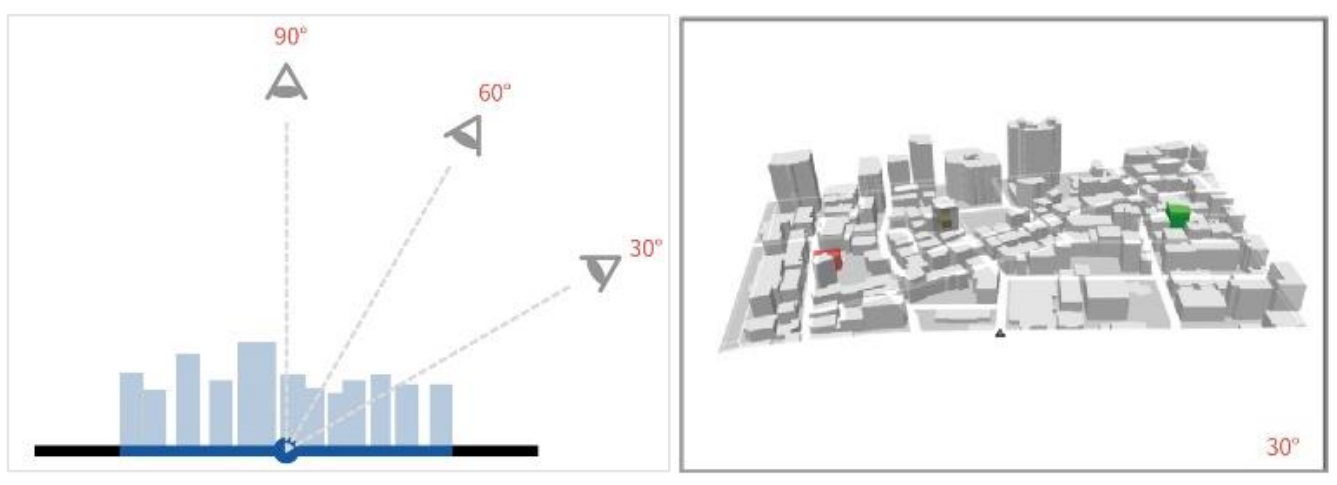

Figure 1. Cont. 

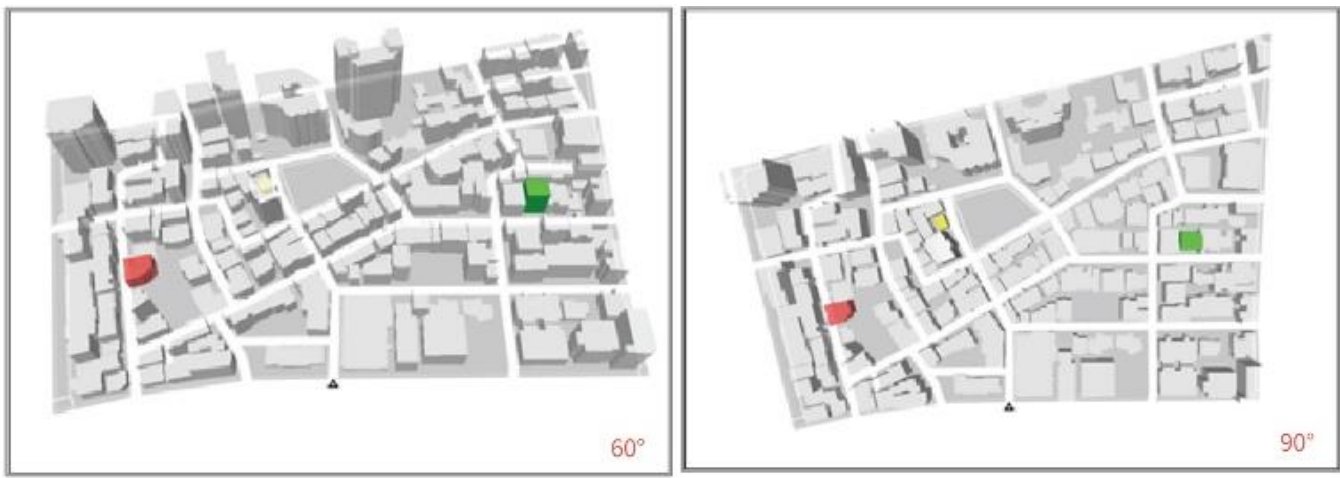

Figure 1. Three map view angles.

The experiment had four stages. First, the self-report Sense of Direction QuestionnaireShort Form (SDQ-S) was completed by the participants. Second, a route planning experiment was performed. All participants had to complete route planning within $4 \mathrm{~min}$. The time required to complete the planning was recorded. Third, Rhino and Mapbox were used to simulate wayfinding in the maps, including wayfinding and orientation. The relationship between the time spent and each map was recorded. Finally, semi-structured interviews were conducted. Think-aloud was used in the interviews to record how the participants described their use of the maps, thereby understanding their thoughts and feelings about the procedure.

\subsection{Experiment Two: Design Verification}

The second experiment had the same four stages as the first experiment. Wayfinding was performed in an actual environment. The participants used a new map design to explore how changing the graphic design of 2.5D maps can improve wayfinding performance. Limberger et al. indicated that using transparency can help map users visualize road networks and obstacles, and create coherent effects. However, transparency might not be suitable for maps with densely placed buildings because the shape of a single building and its relation to other buildings can distract users. Therefore, the basic principle of using transparency is to avoid obstruction from affecting wayfinding. When part of a building obstructed a road in the map design, the part was changed to a semitransparent color, thereby helping users navigate and read the map (Figure 2). Transparency was set according to areas of interest color coded by Google maps, as shown in Figure 3. The transparency was set at $30 \%$ for all areas other than areas of interest to increase the contrast.

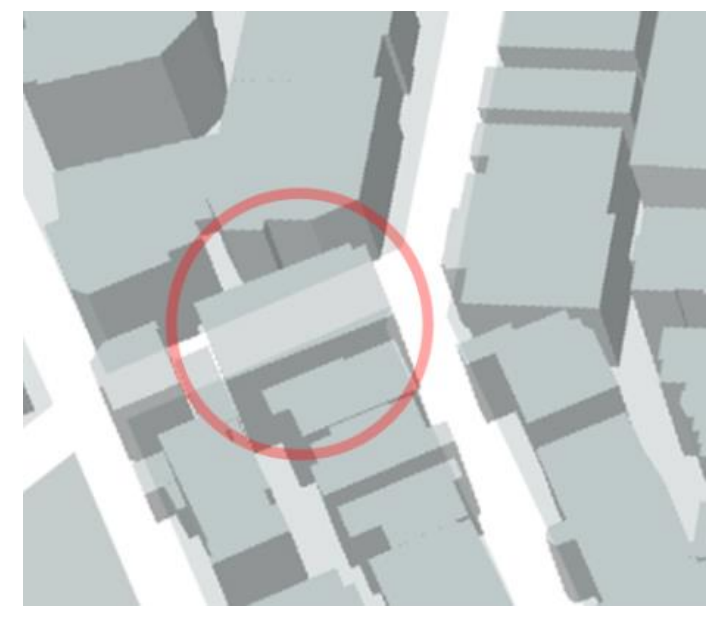

Figure 2. Presentation of transparency in maps. 

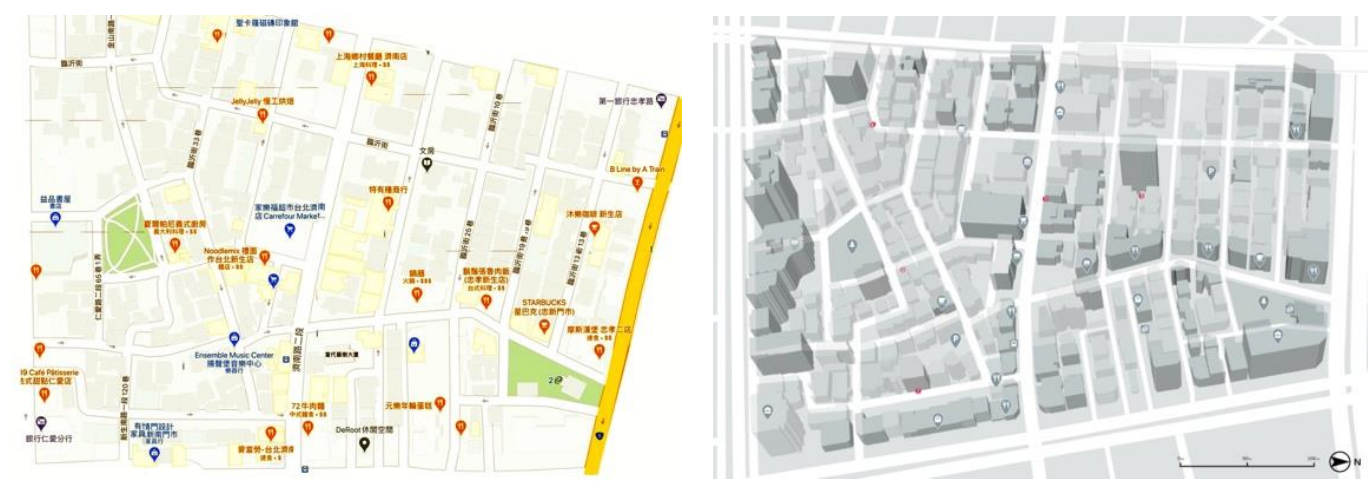

Figure 3. Transparency adjusted according to Google maps' areas of interest.

In addition to transparency, methods of highlighting key landmarks or buildings near mission markers were explored with different transparency settings. Buildings related to a mission marker or taller buildings nearby were selected, and lines were used to border the building images for emphasizing purpose. Actual physical features of buildings were also drawn onto the image with lines to compare the difference between maps with and without the addition of lines (Figure 4). All experimental samples are designed by us individually. Transparency and lines are fixed, not automatically realized.
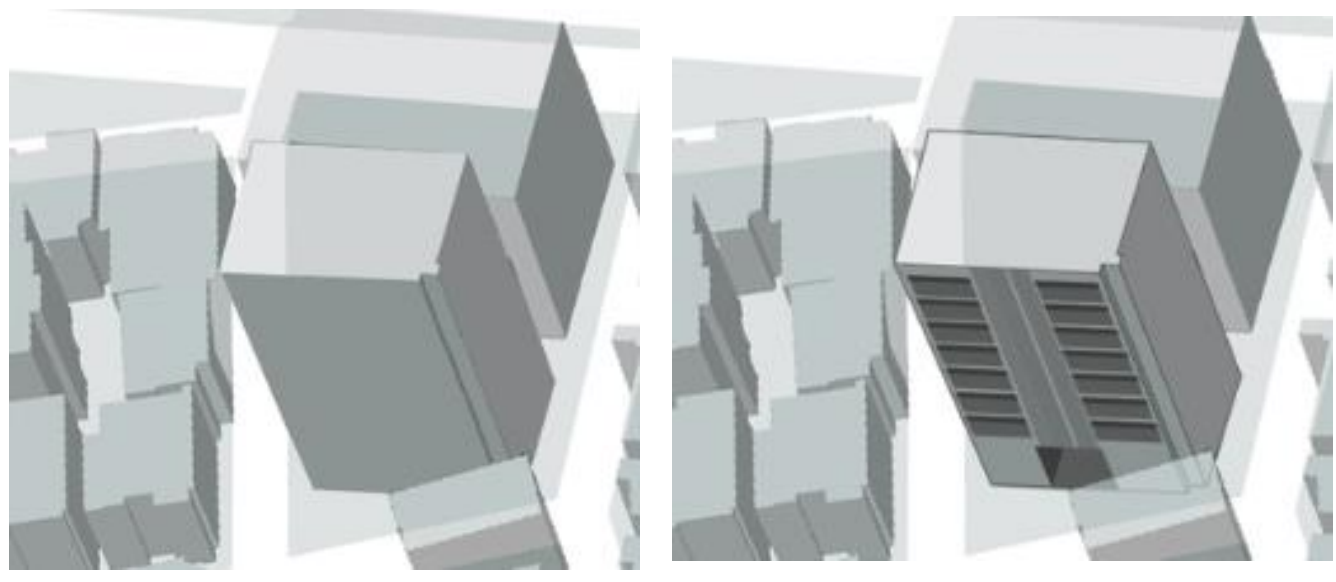

Figure 4. Presentation of lines in maps.

Experiment two involved 32 participants, 20-30 years old, half male and half female who had never moved to this area before. Each completed the SDQ-S at the start. Four map designs (groups A-D) were employed, with each design using a different setting for transparency and lines, as shown in Table 1. Each group had eight participants (four male and four female) chosen at random. Five mission markers were assigned, and all groups had $4 \mathrm{~min}$ to plan routes. The participants were asked to think-aloud during the experiment for the present study to understand their experiences as they walked. While the participants read the map, they were required to use their fingers to follow along the part of the map that they were reading for wayfinding and orientation. Semi-structured interviews were conducted afterwards. 
Table 1. Map designs in experiment two.

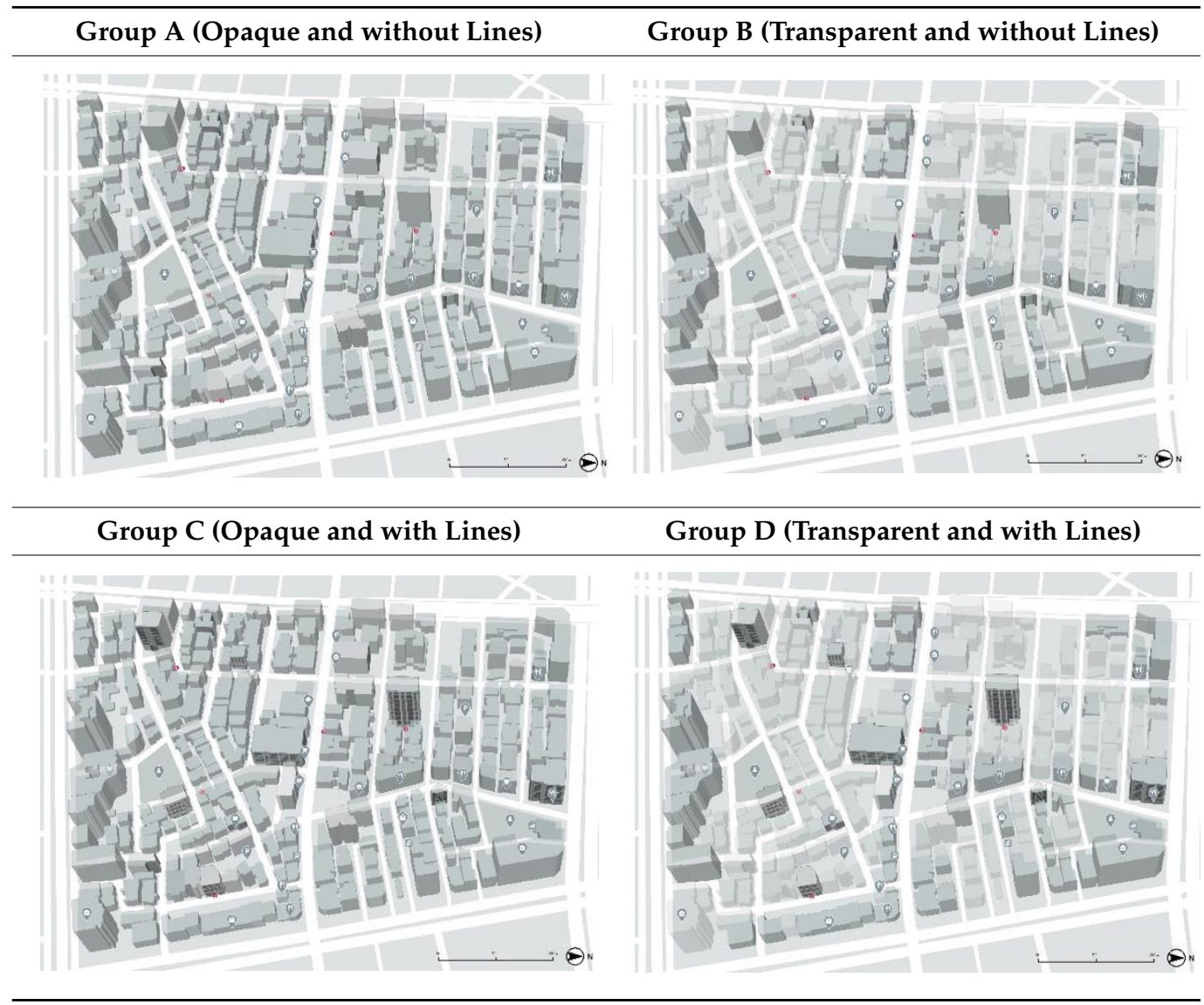

\section{Results}

\subsection{Experiment One}

During route planning, most participants memorized the route by memorizing the number of left and right turns (WD-1) and the number of intersections (WD-2), as shown in Table 2. Most participants were confused (WD-6) at turning points of an intersection; $69 \%$ of the participants using the $\mathrm{H} 30^{\circ}$ map had this problem, the highest ratio among the six types of map. In addition, $71 \%$ of all mission markers were unnoticed or ignored by the group (WD-7). Main roads, protruding buildings, and vacant lots were crucial references that participants used for orientation. Participants often used the relative position between two points (M3) to memorize the route, followed by graphic memory (M2), doubling back along a route (M4), using buildings for memory assistance (M1), and rehearsing the route silently (M5). During the experiment, the participants used buildings on the map to assist them. They memorized buildings as locations where they had to turn or memorize the relative position of buildings from mission markers; $27 \%$ of the $\mathrm{H}^{\circ} 0^{\circ}$ group used buildings in this manner, the highest ratio among the map types. Of the participants who used the $\mathrm{H} 90^{\circ}$ map, $24 \%$ used graphic memory to help with memorization. They memorized roads by imagining them as familiar shapes, such as the shape of a lightning bolt or the letter " $U$ ". The ratio of participants who rehearsed the route silently to memorize it differed according to whether a perspective map or a $90^{\circ}$ planimetric map was used. The number of participants who "crammed" information and rehearsed the route silently increased as the view angle increased (Table 3). 
Table 2. Route planning in experiment one.

\begin{tabular}{|c|c|c|c|c|c|c|c|c|c|}
\hline Code & Description & & $\mathrm{H}^{\circ} 0^{\circ}$ & $\mathrm{H} 60^{\circ}$ & $\mathrm{H} 90^{\circ}$ & ${\mathrm{L} 30^{\circ}}^{\circ}$ & $\mathrm{L}^{\circ} 0^{\circ}$ & $\mathrm{L90}^{\circ}$ & Total \\
\hline \multirow{2}{*}{ WD-1 } & \multirow{2}{*}{ Left and right turns } & All participants & $15 \%$ & $14 \%$ & $17 \%$ & $19 \%$ & $16 \%$ & $19 \%$ & $100 \%$ \\
\hline & & $\%$ within the group & $54 \%$ & $65 \%$ & $58 \%$ & $57 \%$ & $73 \%$ & $66 \%$ & $374 \%$ \\
\hline \multirow{2}{*}{ WD-2 } & \multirow{2}{*}{ Intersection } & All participants & $13 \%$ & $10 \%$ & $22 \%$ & $25 \%$ & $11 \%$ & $18 \%$ & $100 \%$ \\
\hline & & $\%$ within the group & $19 \%$ & $19 \%$ & $29 \%$ & $29 \%$ & $19 \%$ & $25 \%$ & $140 \%$ \\
\hline \multirow{2}{*}{ WD-3 } & \multirow{2}{*}{ Block } & All participants & $24 \%$ & $10 \%$ & $5 \%$ & $62 \%$ & $0 \%$ & $0 \%$ & $100 \%$ \\
\hline & & $\%$ within the group & $2 \%$ & $1 \%$ & $0 \%$ & $3 \%$ & $0 \%$ & $0 \%$ & $6 \%$ \\
\hline \multirow{2}{*}{ WD-4 } & \multirow{2}{*}{ Main roads } & All participants & $19 \%$ & $33 \%$ & $22 \%$ & $4 \%$ & $22 \%$ & $0 \%$ & $100 \%$ \\
\hline & & $\%$ within the group & $2 \%$ & $3 \%$ & $2 \%$ & $0 \%$ & $2 \%$ & $0 \%$ & $9 \%$ \\
\hline \multirow{2}{*}{ WD-5 } & \multirow{2}{*}{$\begin{array}{l}\text { Going straight to the } \\
\text { end }\end{array}$} & All participants & $18 \%$ & $14 \%$ & $24 \%$ & $19 \%$ & $8 \%$ & $18 \%$ & $100 \%$ \\
\hline & & $\%$ within the group & $9 \%$ & $9 \%$ & $11 \%$ & $8 \%$ & $5 \%$ & $9 \%$ & $50 \%$ \\
\hline \multirow{2}{*}{ WD-6 } & \multirow{2}{*}{ Confusion } & All participants & $69 \%$ & $12 \%$ & $0 \%$ & $14 \%$ & $4 \%$ & $0 \%$ & $100 \%$ \\
\hline & & $\%$ within the group & $10 \%$ & $2 \%$ & $0 \%$ & $2 \%$ & $1 \%$ & $0 \%$ & $15 \%$ \\
\hline \multirow{2}{*}{ WD-7 } & \multirow{2}{*}{ Unnoticed or ignored } & All participants & $71 \%$ & $14 \%$ & $0 \%$ & $10 \%$ & $0 \%$ & $5 \%$ & $100 \%$ \\
\hline & & $\%$ within the group & $5 \%$ & $1 \%$ & $0 \%$ & $0 \%$ & $0 \%$ & $0 \%$ & $6 \%$ \\
\hline \multirow{2}{*}{\multicolumn{2}{|c|}{ total }} & $\begin{array}{l}\text { All route planning } \\
\text { descriptions }\end{array}$ & $33 \%$ & $15 \%$ & $13 \%$ & $22 \%$ & $9 \%$ & $8 \%$ & $100 \%$ \\
\hline & & $\%$ within the group & $100 \%$ & $100 \%$ & $100 \%$ & $100 \%$ & $100 \%$ & $100 \%$ & $600 \%$ \\
\hline
\end{tabular}

Table 3. Memorization methods in experiment one.

\begin{tabular}{|c|c|c|c|c|c|c|c|c|c|}
\hline Code & Description & & $\mathrm{H} 30^{\circ}$ & $\mathrm{H} 60^{\circ}$ & $\mathrm{H} 90^{\circ}$ & $\mathrm{L}^{3} 0^{\circ}$ & $\mathrm{L}^{\circ} 0^{\circ}$ & $\mathrm{L90}^{\circ}$ & Total \\
\hline \multirow{2}{*}{ M1 } & \multirow{2}{*}{ Building } & All participants & $24 \%$ & $27 \%$ & $22 \%$ & $8 \%$ & $14 \%$ & $5 \%$ & $100 \%$ \\
\hline & & $\%$ within the group & $19 \%$ & $20 \%$ & $13 \%$ & $8 \%$ & $11 \%$ & $5 \%$ & $75 \%$ \\
\hline \multirow{2}{*}{ M2 } & \multirow{2}{*}{ Graphic memory } & All participants & $17 \%$ & $20 \%$ & $24 \%$ & $14 \%$ & $12 \%$ & $14 \%$ & $100 \%$ \\
\hline & & $\%$ within the group & $21 \%$ & $24 \%$ & $22 \%$ & $21 \%$ & $16 \%$ & $19 \%$ & $122 \%$ \\
\hline \multirow{2}{*}{ M3 } & \multirow{2}{*}{ Relative position } & All participants & $16 \%$ & $18 \%$ & $18 \%$ & $16 \%$ & $21 \%$ & $12 \%$ & $100 \%$ \\
\hline & & $\%$ within the group & $23 \%$ & $24 \%$ & $19 \%$ & $29 \%$ & $32 \%$ & $19 \%$ & $145 \%$ \\
\hline \multirow{2}{*}{ M4 } & \multirow{2}{*}{ Doubling back } & All participants & $17 \%$ & $21 \%$ & $21 \%$ & $23 \%$ & $6 \%$ & $13 \%$ & $100 \%$ \\
\hline & & $\%$ within the group & $17 \%$ & $20 \%$ & $16 \%$ & $29 \%$ & $7 \%$ & $14 \%$ & $102 \%$ \\
\hline \multirow{2}{*}{ M5 } & \multirow{2}{*}{ Silent rehearsal } & All participants & $13 \%$ & $9 \%$ & $26 \%$ & $7 \%$ & $20 \%$ & $25 \%$ & $100 \%$ \\
\hline & & $\%$ within the group & $21 \%$ & $14 \%$ & $31 \%$ & $13 \%$ & $34 \%$ & $44 \%$ & $157 \%$ \\
\hline & \multirow{2}{*}{ total } & All participants & $17 \%$ & $19 \%$ & $22 \%$ & $13 \%$ & $14 \%$ & $14 \%$ & $100 \%$ \\
\hline & & $\%$ within the group & $100 \%$ & $100 \%$ & $100 \%$ & $100 \%$ & $100 \%$ & $100 \%$ & $600 \%$ \\
\hline
\end{tabular}

The average time required to complete the first simulated wayfinding task was $255.4 \mathrm{~s}$, making it the most time consuming. A possible explanation is that the participants had not yet familiarized themselves with map reading and software operations, thus, they spent relatively more time searching for mission markers. Compared with those who used $30^{\circ}$ or $60^{\circ}$ maps, participants who used a $90^{\circ}$ map spent less time on average memorizing the map; $90^{\circ}$ maps have clear and unobstructed roads, and the layout is more spaced out. Therefore, the participants who used these maps required less memorization time. However, during simulated wayfinding, these participants had to "transform" the map into a 3D layout. Thus, compared with other participants, they required more time for spatial transformation. For all tasks, the groups using high-density maps required an average of $203.3 \mathrm{~s}$, whereas groups that used low-density maps required an average of $168.1 \mathrm{~s}$. The 
difference was significant (first task: $p=0.046<0.05$ ). Participants who used $90^{\circ}$ maps required $196.6 \mathrm{~s}$, whereas their counterparts who used $60^{\circ}$ maps and $30^{\circ}$ maps required $177.7 \mathrm{~s}$ and $182.8 \mathrm{~s}$, respectively. Those using $90^{\circ}$ maps spent more time on average in simulated wayfinding, and this finding corresponds with the findings of Zanola et al., which indicated that perspective maps can improve spatial transformation abilities. Maps with larger view angles assisted with map memorization, but they affected simulated wayfinding performance (Table 4).

Table 4. Time required for route planning and simulated wayfinding in experiment one.

\begin{tabular}{|c|c|c|c|c|c|c|c|c|c|c|c|c|c|c|}
\hline \multicolumn{8}{|c|}{ Route Planning } & \multicolumn{7}{|c|}{ Wayfinding Simulation } \\
\hline Task & $\mathrm{H} 30^{\circ}$ & $\mathrm{H} 60^{\circ}$ & $\mathrm{H} 90^{\circ}$ & ${\mathrm{L} 30^{\circ}}^{\circ}$ & $\mathbf{L 6 0}^{\circ}$ & $\mathrm{L90}^{\circ}$ & Average & $\mathrm{H} 30^{\circ}$ & $\mathrm{H} 60^{\circ}$ & $\mathrm{H}^{\circ} \mathrm{o}^{\circ}$ & $\mathrm{L}^{\circ} 0^{\circ}$ & $\mathrm{L60}^{\circ}$ & $\mathrm{L}^{\circ} 0^{\circ}$ & Average \\
\hline 1 & $229.7^{\prime \prime}$ & $225.3^{\prime \prime}$ & $190.0^{\prime \prime}$ & $209.3^{\prime \prime}$ & $227.0^{\prime \prime}$ & $238.3^{\prime \prime}$ & $219.9^{\prime \prime}$ & $286.8^{\prime \prime}$ & $295.2^{\prime \prime}$ & $373.8^{\prime \prime}$ & $160.2^{\prime \prime}$ & $201.8^{\prime \prime}$ & $214.3^{\prime \prime}$ & $255.4^{\prime \prime}$ \\
\hline 2 & $232.7^{\prime \prime}$ & $199.2^{\prime \prime}$ & $197.2^{\prime \prime}$ & $216.7^{\prime \prime}$ & $215.3^{\prime \prime}$ & $216.7^{\prime \prime}$ & $212.9^{\prime \prime}$ & $143.0^{\prime \prime}$ & $118.8^{\prime \prime}$ & $113.5^{\prime \prime}$ & $116.8^{\prime \prime}$ & $115.5^{\prime \prime}$ & $143.7^{\prime \prime}$ & $125.2^{\prime \prime}$ \\
\hline 3 & $233.3^{\prime \prime}$ & $236.5^{\prime \prime}$ & $227.0^{\prime \prime}$ & $229.3^{\prime \prime}$ & $229.0^{\prime \prime}$ & $234.5^{\prime \prime}$ & $231.6^{\prime \prime}$ & $216.3^{\prime \prime}$ & $166.3^{\prime \prime}$ & $235.8^{\prime \prime}$ & $243.3^{\prime \prime}$ & $227.5^{\prime \prime}$ & $191.2^{\prime \prime}$ & $213.4^{\prime \prime}$ \\
\hline 4 & $224.3^{\prime \prime}$ & $219.3^{\prime \prime}$ & $230.8^{\prime \prime}$ & $221.8^{\prime \prime}$ & $220.5^{\prime \prime}$ & $218.5^{\prime \prime}$ & $222.6^{\prime \prime}$ & $157.3^{\prime \prime}$ & $168.0^{\prime \prime}$ & $164.2^{\prime \prime}$ & $138.2^{\prime \prime}$ & $128.6^{\prime \prime}$ & $136.5^{\prime \prime}$ & $148.8^{\prime \prime}$ \\
\hline \multirow{2}{*}{ average } & $230.0^{\prime \prime}$ & $220.1^{\prime \prime}$ & $211.3^{\prime \prime}$ & $219.3^{\prime \prime}$ & $223.0^{\prime \prime}$ & $227.0^{\prime \prime}$ & \multirow{2}{*}{$221.8^{\prime \prime}$} & $200.9^{\prime \prime}$ & $187.1^{\prime \prime}$ & $221.8^{\prime \prime}$ & $164.6^{\prime \prime}$ & $168.4^{\prime \prime}$ & $171.4^{\prime \prime}$ & \multirow{2}{*}{$185.7^{\prime \prime}$} \\
\hline & & $220.4^{\prime \prime}$ & & & $223.1^{\prime \prime}$ & & & & $203.3^{\prime \prime}$ & & & $168.1^{\prime \prime}$ & & \\
\hline
\end{tabular}

The results of two-way analysis of variance indicated that during route planning, the frequency of participants expressing confusion (WD-6) was significantly correlated with the view angle and the building density of the map ( $p=0.0329$ and $p=1.66$, respectively). The results for three of the four tasks indicated that the interaction between view angle and density was significantly correlated with the frequency of participants expressing confusion (WD-6); the $p$ values for tasks 1,2 , and 4 were $0.0393,0.03149$, and 0.0004 , respectively.

Participants who used $30^{\circ}$ maps expressed confusion most often during route planning, followed by participants who used $60^{\circ}$ maps. Participants who used $90^{\circ}$ maps did not express confusion in any of the tasks. Participants who used high-density maps expressed confusion with higher frequency relative to those who used low-density maps. In general, the participants who used $\mathrm{H} 30^{\circ}$ maps experienced confusion most often, whereas those who used $\mathrm{L} 90^{\circ}$ maps experienced confusion least often. Map users struggled to process the large amount of information on maps and were affected by obstructive landmarks.

During wayfinding simulations, confusion or hesitation (WK-1), doubling back (WK-2), and going off-route (WK-3) affected wayfinding performance. The users of high-density maps exhibited these phenomena more frequently. During the test determining the consistency of the taken route with the cognitive map, $\mathrm{L} 60^{\circ}$ map users had the highest consistency $(41.7 \%)$, followed by those using $\mathrm{L} 30^{\circ}$ maps and $\mathrm{H} 60^{\circ}$ maps. Those using of $90^{\circ}$ maps had a lower consistency. Although the roads of $90^{\circ}$ maps are not obstructed, $90^{\circ}$ maps do not have protruding elements that can serve as memory references as do perspective maps. A higher proportion of participants who used $90^{\circ}$ maps relied on silent rehearsal to memorize routes (Table 5). This verified the findings of You et al. regarding the problem of transforming 2D and 3D spaces. A comparison of the consistency for the perspective maps, namely $\mathrm{H} 30^{\circ}, \mathrm{H}_{60}{ }^{\circ}, \mathrm{L} 30^{\circ}$, and $\mathrm{L} 60^{\circ}$ maps, indicated that a higher consistency between the taken route and the cognitive map was observed in users of low-density maps.

High-density map users exhibited confusion and hesitation more frequently $(18.5 \%)$ than did low-density map users (14.8\%). High-density map users also doubled back more frequently $(20.1 \%)$ than low-density map users $(13.3 \%)$. The chance of going off-route was higher for high-density (22.5\%) than for low-density (10.8\%) map users. In addition, the consistency between the taken route and the cognitive map was higher for low-density map users (29.2\%) than for high-density map users (23.6\%). The orientation error rate of low-density map users was $8.4 \%$, higher than that of high-density map users $(7.7 \%)$. The results are presented in Table 6. 
Table 5. Simulated wayfinding behavior for low- and high-density maps.

\begin{tabular}{|c|c|c|c|c|c|c|c|c|c|}
\hline Code & Behavior & & $\mathrm{H} 30^{\circ}$ & $\mathrm{H} 60^{\circ}$ & $\mathrm{H} 90^{\circ}$ & $\mathrm{L}^{3} 0^{\circ}$ & $\mathrm{L}^{6} 0^{\circ}$ & $\mathrm{L}^{\circ} 0^{\circ}$ & Total \\
\hline \multirow{2}{*}{ WK-1 } & \multirow{2}{*}{$\begin{array}{l}\text { Confusion and } \\
\text { hesitation }\end{array}$} & All participants & $20.3 \%$ & $14.4 \%$ & $20.9 \%$ & $17.6 \%$ & $10.5 \%$ & $16.3 \%$ & $100 \%$ \\
\hline & & $\%$ within the group & $32.6 \%$ & $45.8 \%$ & $27.8 \%$ & $43.5 \%$ & $33.3 \%$ & $36.8 \%$ & $220 \%$ \\
\hline \multirow{2}{*}{ WK-2 } & \multirow{2}{*}{ Doubling back } & All participants & $23.2 \%$ & $8.5 \%$ & $28.5 \%$ & $13.4 \%$ & $11.4 \%$ & $15.0 \%$ & $100 \%$ \\
\hline & & $\%$ within the group & $60.0 \%$ & $43.8 \%$ & $60.9 \%$ & $53.2 \%$ & $58.3 \%$ & $54.4 \%$ & $331 \%$ \\
\hline \multirow{2}{*}{ WK-3 } & \multirow{2}{*}{ Going off-route } & All participants & $18.9 \%$ & $13.5 \%$ & $35.1 \%$ & $5.4 \%$ & $10.8 \%$ & $16.2 \%$ & $100 \%$ \\
\hline & & $\%$ within the group & $7.4 \%$ & $10.4 \%$ & $11.3 \%$ & $3.2 \%$ & $8.3 \%$ & $8.8 \%$ & $49 \%$ \\
\hline \multirow{2}{*}{\multicolumn{2}{|c|}{ Total }} & All wayfinding behavior & $20.8 \%$ & $12.1 \%$ & $28.2 \%$ & $12.2 \%$ & $10.9 \%$ & $15.9 \%$ & $100 \%$ \\
\hline & & $\%$ within the group & $100 \%$ & $100 \%$ & $100 \%$ & $100 \%$ & $100 \%$ & $100 \%$ & $600 \%$ \\
\hline \multirow{3}{*}{\multicolumn{2}{|c|}{ Average, high-density maps }} & Confusion and hesitation & & $18.5 \%$ & & & & & \multirow{3}{*}{$61 \%$} \\
\hline & & Doubling back & & $20.1 \%$ & & & & & \\
\hline & & Going off-route & & $22.5 \%$ & & & & & \\
\hline \multirow{3}{*}{\multicolumn{2}{|c|}{ Average, low-density maps }} & Confusion and hesitation & & & & & $14.8 \%$ & & \multirow{3}{*}{$39 \%$} \\
\hline & & Doubling back & & & & & $13.3 \%$ & & \\
\hline & & Going off-route & & & & & $10.8 \%$ & & \\
\hline
\end{tabular}

Table 6. Consistency between taken route and cognitive map, and mission marker orientation error rate for low- and high-density maps.

\begin{tabular}{|c|c|c|c|c|c|c|c|c|}
\hline & & $\mathrm{H} 30^{\circ}$ & $\mathrm{H} 60^{\circ}$ & $\mathrm{H} 90^{\circ}$ & $\mathrm{L}^{3} 0^{\circ}$ & $\mathrm{L}^{6} 0^{\circ}$ & $\mathrm{L90}^{\circ}$ & Total \\
\hline $\begin{array}{l}\text { Consistency between taken } \\
\text { route and cognitive map }\end{array}$ & All participants & $16.7 \%$ & $29.2 \%$ & $25.0 \%$ & $33.3 \%$ & $41.7 \%$ & $12.5 \%$ & $26.4 \%$ \\
\hline Orientation error rate & All participants & $7.3 \%$ & $7.0 \%$ & $8.8 \%$ & $8.3 \%$ & $7.5 \%$ & $9.4 \%$ & $48.2 \%$ \\
\hline \multirow[t]{2}{*}{ Average, high-density maps } & $\begin{array}{l}\text { Consistency between taken } \\
\text { route and cognitive map }\end{array}$ & & $23.6 \%$ & & & & & \\
\hline & Orientation error rate & & $7.7 \%$ & & & & & \\
\hline \multirow[t]{2}{*}{ Average, low-density maps } & $\begin{array}{l}\text { Consistency between taken } \\
\text { route and cognitive map }\end{array}$ & & & & & $29.2 \%$ & & \\
\hline & Orientation error rate & & & & & $8.4 \%$ & & \\
\hline
\end{tabular}

In general, compared with high-density maps, low-density maps allowed superior performance in simulated wayfinding (including confusion, doubling back, and going off-route) and higher consistency between the taken route and the cognitive map.

The ratios of confusion and hesitation and doubling back for map users of $60^{\circ}$ maps were $24.8 \%$ and $19.9 \%$, respectively, and less than those of users of $30^{\circ}$ and $90^{\circ}$ maps. During the test to determine the consistency between the simulated taken route and the cognitive map, users of $60^{\circ}$ maps reported the highest consistency at $70.8 \%$, followed by $50 \%$ for users of $30^{\circ}$ maps and $37.5 \%$ for users of $90^{\circ}$ maps, as shown in Tables 7 and 8 . The orientation error rate of users of $60^{\circ}$ maps was $14.5 \%$, which was lower than that of users of $30^{\circ}$ maps and $90^{\circ}$ maps ( $15.6 \%$ and $18.1 \%$, respectively).

When $90^{\circ}$ maps are used, users must transform the planimetric map into a 3D layout. Although the ratio of participants who exhibited confusion and hesitation during route planning was lower, the ratio that exhibited confusion and hesitation during simulated wayfinding was much higher. The view angle of $30^{\circ}$ maps was smaller, thus, buildings obstructed the line of sight of users. Users of $60^{\circ}$ maps were able to recognize protruding buildings, thus, compared with $30^{\circ}$ maps, $60^{\circ}$ maps allowed superior performance in simulated wayfinding (avoiding confusion and hesitation, doubling back, and going off- 
route), a higher consistency between the taken route and the cognitive map, and a lower orientation error rate.

Table 7. Simulated wayfinding behavior by view angle.

\begin{tabular}{cllcccc}
\hline Code & Behavior & & $\mathbf{3 0}^{\circ}$ & $\mathbf{6 0}^{\circ}$ & $\mathbf{9 0}^{\circ}$ & Total \\
\hline WK-1 & $\begin{array}{l}\text { Confusion and } \\
\text { hesitation }\end{array}$ & All participants & $37.9 \%$ & $24.8 \%$ & $37.3 \%$ & $100 \%$ \\
\hline WK-2 & Doubling back & All participants & $36.6 \%$ & $19.9 \%$ & $43.5 \%$ & $100 \%$ \\
\hline WK-3 & Going off-route & All participants & $24.3 \%$ & $24.3 \%$ & $51.4 \%$ & $100 \%$ \\
\hline & Total & $\begin{array}{l}\text { Wayfinding } \\
\text { behavior }\end{array}$ & $32.9 \%$ & $23.0 \%$ & $44.0 \%$ & $100 \%$ \\
\hline
\end{tabular}

Table 8. Consistency between taken route and cognitive map, and the mission marker orientation rate according to view angle.

\begin{tabular}{cccccc}
\hline & & $\mathbf{3 0}^{\circ}$ & $\mathbf{6 0}^{\circ}$ & $\mathbf{9 0}^{\circ}$ & Total \\
\hline $\begin{array}{c}\text { Consistency between taken } \\
\text { route and cognitive map }\end{array}$ & All participants & $50.0 \%$ & $70.8 \%$ & $37.5 \%$ & $53 \%$ \\
\hline Orientation error rate & All participants & $15.6 \%$ & $14.5 \%$ & $18.1 \%$ & $16 \%$ \\
\hline
\end{tabular}

Before the experiment, a majority (47.2\%) of participants preferred $90^{\circ}$ maps. After the experiment, the participants were asked their map preference again, and $52.7 \%$ chose $60^{\circ}$ maps; 22 of the 36 participants changed their preference and responded during the interview that $60^{\circ}$ maps were their preferred design (Figure 5).

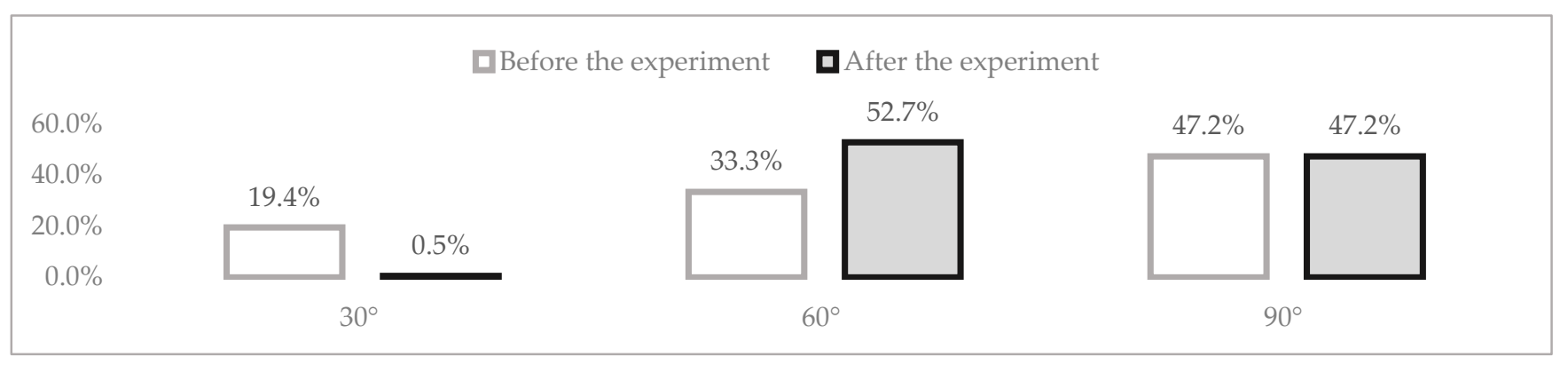

Figure 5. View angle preference before and after experiment one.

\subsection{Experiment Two}

We used the content of Table 1 to assess map designs. The groups were A (opaque), B (opaque with lines), C (transparent), and D (transparent with lines). Map users exhibited more confusion and hesitation (WD-1) when they used maps from group A or B (a ratio of $31 \%$ and $38 \%$, respectively). The reason for this is that opaque buildings obstructed the roads, and the participants were unable to identify the correct location. However, only $6 \%$ of participants expressed confusion or hesitation. Participants in the first experiment were generally confused and hesitant at intersections; therefore, the second experiment included landmarks at intersections, which successfully reduced confusion and hesitation. An example is shown in Figure 6.

Participants often used the number of left and right turns (WD-3) and intersections (WD-4) in route planning. When they were unable to see intersections clearly, they used alleys (WD-5) to describe the route instead. The main principle in route planning was to attempt to follow the road (WD-11) and avoid turns or narrow passages. Participants with a poorer sense of direction doubled back (WD-7). They preferred familiar routes and avoided memorizing additional routes. Relative position (WD-6) was often used in conjunction with mission markers or landmarks (WD-2), and group D used relative position most often 
(39\%). When the participants read a map and described buildings, they used landmarks to plan their route. Group D map users mentioned landmarks most frequently $(35 \%)$, as shown in Table 9. When a mission marker was located next to a tall protruding building, the participants usually referenced the building. However, when a mission marker was located in a residential area, most participants used intersections and left/right turns to plan routes and searched for intersections, landmarks, and main roads to orientate. The landmarks referenced by participants were usually located at intersections or objects that were obvious and unique (Figure 7). Maps with lines helped participants notice landmarks more easily.

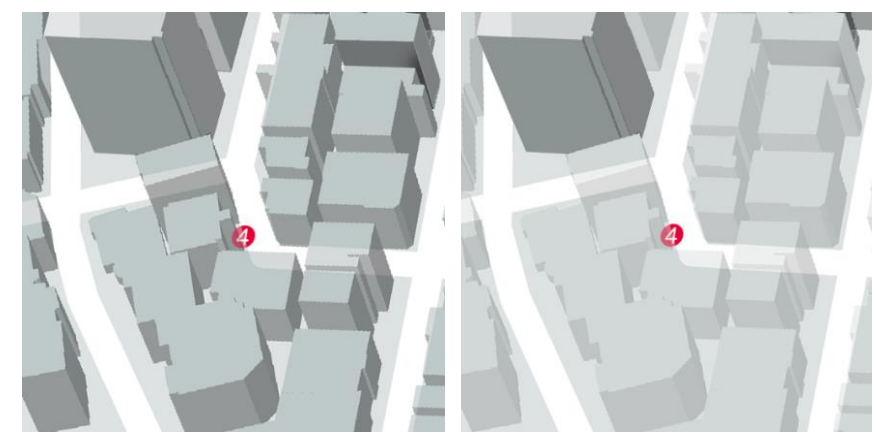

Figure 6. Example of road obstruction by buildings. (Opaque/Transparent).
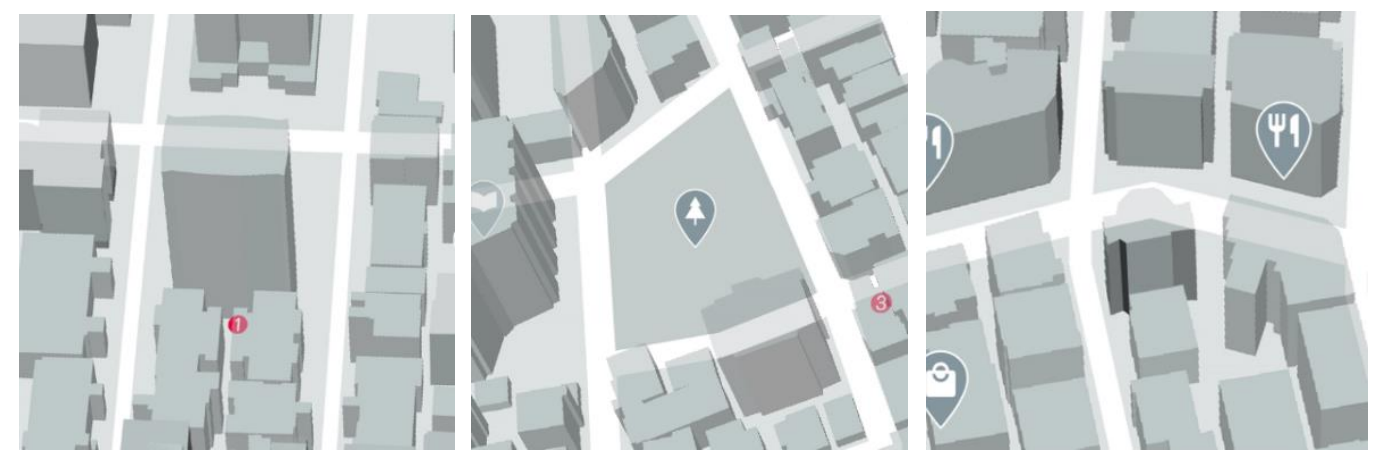

Figure 7. Example of a protruding landmark in a group A map in experiment two.

In two-way analysis of variance, the expression of confusion and hesitation during route planning was significantly correlated with the existence of lines on the maps $(p=0.0201)$. Participants who used a map without lines expressed significantly more confusion and hesitation than those using a map with lines.

Table 10 presents the time required by the participants to complete the wayfinding tasks. The average time required from shortest to longest was as follows: group D $\left(21^{\prime} 38^{\prime \prime}\right)$, group A $\left(23^{\prime} 31^{\prime \prime}\right)$, group B $\left(24^{\prime} 57^{\prime \prime}\right)$, and group C $\left(25^{\prime} 58^{\prime \prime}\right)$. Group D claimed that at first sight, their map was clear and easy to read because of due its transparency and lines. Group A mentioned that the opaque map, although equipped with the essential information of a map, required much time to read. Group B commented that their map was "messy" at first sight and required much time to read; moreover, the lines on the map were not helpful and hindered their line of sight. Group $C$ stated that their map seemed useful at first sight, but lacked focus due to the transparency, and thus rendering orientation a time-consuming process.

As wayfinding behavior is a series of continual actions, we examined ineffective behavior that participants exhibited while using the maps. Confusion and hesitation (BC) and becoming lost (BL) were selected as examples. Figure 8 presents the data for confusion/hesitation and becoming lost (Table 11). Group D exhibited the lowest frequency of ineffective wayfinding behavior (10\%), followed by group C (27\%), group A ( $29 \%)$, and group B (35\%). 
Table 9. Route planning in experiment two.

\begin{tabular}{|c|c|c|c|c|c|c|c|}
\hline Code & Description & & $\begin{array}{c}\text { Group A } \\
\text { (Opaque) }\end{array}$ & $\begin{array}{c}\text { Group B } \\
\text { (Opaque } \\
\text { with Lines) }\end{array}$ & $\begin{array}{l}\text { Group C } \\
\text { (Transpar- } \\
\text { ent) }\end{array}$ & $\begin{array}{c}\text { Group D } \\
\text { (Transparent } \\
\text { with Lines) }\end{array}$ & Total \\
\hline \multirow{2}{*}{ WD-1 } & \multirow{2}{*}{$\begin{array}{l}\text { Confusion and } \\
\text { hesitation }\end{array}$} & All participants & $31 \%$ & $38 \%$ & $15 \%$ & $15 \%$ & $100 \%$ \\
\hline & & $\%$ within the group & $2 \%$ & $3 \%$ & $1 \%$ & $1 \%$ & $6 \%$ \\
\hline \multirow{2}{*}{ WD-2 } & \multirow{2}{*}{ Landmark } & All participants & $31 \%$ & $18 \%$ & $16 \%$ & $35 \%$ & $100 \%$ \\
\hline & & $\%$ within the group & $26 \%$ & $18 \%$ & $15 \%$ & $22 \%$ & $80 \%$ \\
\hline \multirow{2}{*}{ WD-3 } & \multirow{2}{*}{$\begin{array}{l}\text { Left and right } \\
\text { turns }\end{array}$} & All participants & $23 \%$ & $20 \%$ & $24 \%$ & $33 \%$ & $100 \%$ \\
\hline & & $\%$ within the group & $24 \%$ & $26 \%$ & $28 \%$ & $27 \%$ & $105 \%$ \\
\hline \multirow{2}{*}{ WD-4 } & \multirow{2}{*}{ Intersection } & All participants & $17 \%$ & $22 \%$ & $23 \%$ & $38 \%$ & $100 \%$ \\
\hline & & $\%$ within the group & $10 \%$ & $15 \%$ & $15 \%$ & $17 \%$ & $57 \%$ \\
\hline \multirow{2}{*}{ WD-5 } & \multirow{2}{*}{ Alley } & All participants & $29 \%$ & $29 \%$ & $25 \%$ & $17 \%$ & $100 \%$ \\
\hline & & $\%$ within the group & $3 \%$ & $4 \%$ & $3 \%$ & $1 \%$ & $11 \%$ \\
\hline \multirow{2}{*}{ WD-6 } & \multirow{2}{*}{ Relative position } & All participants & $27 \%$ & $18 \%$ & $16 \%$ & $39 \%$ & $100 \%$ \\
\hline & & $\%$ within the group & $5 \%$ & $4 \%$ & $3 \%$ & $6 \%$ & $19 \%$ \\
\hline \multirow{2}{*}{ WD-7 } & \multirow{2}{*}{ Double back } & All participants & $19 \%$ & $16 \%$ & $30 \%$ & $35 \%$ & $100 \%$ \\
\hline & & $\%$ within the group & $4 \%$ & $4 \%$ & $6 \%$ & $5 \%$ & $19 \%$ \\
\hline \multirow{2}{*}{ WD-8 } & \multirow{2}{*}{ Distance } & All participants & $26 \%$ & $26 \%$ & $42 \%$ & $5 \%$ & $100 \%$ \\
\hline & & $\%$ within the group & $2 \%$ & $3 \%$ & $4 \%$ & $0 \%$ & $9 \%$ \\
\hline \multirow{2}{*}{ WD-9 } & \multirow{2}{*}{$\begin{array}{l}\text { Going straight to } \\
\text { the end }\end{array}$} & All participants & $24 \%$ & $40 \%$ & $12 \%$ & $24 \%$ & $100 \%$ \\
\hline & & $\%$ within the group & $3 \%$ & $5 \%$ & $1 \%$ & $2 \%$ & $11 \%$ \\
\hline \multirow{2}{*}{ WD-10 } & \multirow{2}{*}{ Main road } & All participants & $21 \%$ & $18 \%$ & $29 \%$ & $32 \%$ & $100 \%$ \\
\hline & & $\%$ within the group & $3 \%$ & $3 \%$ & $5 \%$ & $4 \%$ & $15 \%$ \\
\hline \multirow{2}{*}{ WD-11 } & \multirow{2}{*}{ Following the road } & All participants & $29 \%$ & $21 \%$ & $22 \%$ & $29 \%$ & $100 \%$ \\
\hline & & $\%$ within the group & $16 \%$ & $14 \%$ & $14 \%$ & $12 \%$ & $56 \%$ \\
\hline \multirow{2}{*}{ WD-12 } & \multirow{2}{*}{ Shape } & All participants & $17 \%$ & $21 \%$ & $33 \%$ & $29 \%$ & $100 \%$ \\
\hline & & $\%$ within the group & $2 \%$ & $3 \%$ & $4 \%$ & $2 \%$ & $11 \%$ \\
\hline \multirow[t]{2}{*}{ total } & & $\begin{array}{l}\text { All route planning } \\
\text { descriptions }\end{array}$ & $24 \%$ & $24 \%$ & $24 \%$ & $28 \%$ & $100 \%$ \\
\hline & & $\%$ within the group & $100 \%$ & $100 \%$ & $100 \%$ & $100 \%$ & $400 \%$ \\
\hline
\end{tabular}

Table 10. Average time required to complete wayfinding tasks in experiment two.

\begin{tabular}{ccccc}
\hline & $\begin{array}{c}\text { Group A } \\
\text { (Opaque) }\end{array}$ & $\begin{array}{c}\text { Group B } \\
\text { (Opaque and } \\
\text { with Lines) }\end{array}$ & $\begin{array}{c}\text { Group C } \\
\text { (Transparent) }\end{array}$ & $\begin{array}{c}\text { Group D } \\
\text { (Transparent } \\
\text { and with Lines) }\end{array}$ \\
\hline Total Time & $23^{\prime} 31^{\prime \prime}$ & $24^{\prime} 57^{\prime \prime}$ & $25^{\prime} 58^{\prime \prime}$ & $21^{\prime} 38^{\prime \prime}$ \\
\hline Task1 & $04^{\prime} 15^{\prime \prime}$ & $03^{\prime} 22^{\prime \prime}$ & $03^{\prime} 32^{\prime \prime}$ & $02^{\prime} 44^{\prime \prime}$ \\
\hline Task2 & $04^{\prime} 34^{\prime \prime}$ & $05^{\prime} 11^{\prime \prime}$ & $05^{\prime} 26^{\prime \prime}$ & $04^{\prime} 36^{\prime \prime}$ \\
\hline Task3 & $03^{\prime} 17^{\prime \prime}$ & $03^{\prime} 48^{\prime \prime}$ & $03^{\prime} 11^{\prime \prime}$ & $02^{\prime} 42^{\prime \prime}$ \\
\hline Task4 & $02^{\prime} 58^{\prime \prime}$ & $03^{\prime} 37^{\prime \prime}$ & $03^{\prime} 38^{\prime \prime}$ & $03^{\prime} 10^{\prime \prime}$ \\
\hline Task5 & $04^{\prime} 28^{\prime \prime}$ & $05^{\prime} 02^{\prime \prime}$ & $05^{\prime} 39^{\prime \prime}$ & $04^{\prime} 15^{\prime \prime}$ \\
\hline Back to start & $03^{\prime} 59^{\prime \prime}$ & $03^{\prime} 57^{\prime \prime}$ & $04^{\prime} 33^{\prime \prime}$ & $04^{\prime} 12^{\prime \prime}$ \\
\hline
\end{tabular}


Table 11. Ratios for wayfinding behavior in experiment two.

\begin{tabular}{|c|c|c|c|c|c|c|c|}
\hline Code & Description & & $\begin{array}{c}\text { Group A } \\
\text { (Opaque) }\end{array}$ & $\begin{array}{c}\text { Group B } \\
\text { (Opaque } \\
\text { with Lines) }\end{array}$ & $\begin{array}{l}\text { Group C } \\
\text { (Transparent) }\end{array}$ & $\begin{array}{c}\text { Group D } \\
\text { (Transparent } \\
\text { with Lines) }\end{array}$ & Total \\
\hline \multirow{2}{*}{$\mathrm{BC}$} & \multirow{2}{*}{$\begin{array}{l}\text { Confusion and } \\
\text { hesitation }\end{array}$} & All participants & $24 \%$ & $36 \%$ & $29 \%$ & $11 \%$ & $100 \%$ \\
\hline & & $\%$ within the group & $5 \%$ & $5 \%$ & $5 \%$ & $2 \%$ & $17 \%$ \\
\hline \multirow{2}{*}{$\mathrm{BB}$} & \multirow{2}{*}{ Doubling back } & All participants & $30 \%$ & $39 \%$ & $25 \%$ & $7 \%$ & $100 \%$ \\
\hline & & $\%$ within the group & $2 \%$ & $2 \%$ & $2 \%$ & $0 \%$ & $7 \%$ \\
\hline \multirow{2}{*}{ BTW } & \multirow{2}{*}{$\begin{array}{l}\text { Looking around } \\
\text { horizontally }\end{array}$} & All participants & $22 \%$ & $30 \%$ & $23 \%$ & $25 \%$ & $100 \%$ \\
\hline & & $\%$ within the group & $21 \%$ & $22 \%$ & $19 \%$ & $22 \%$ & $84 \%$ \\
\hline \multirow{2}{*}{ BWM } & \multirow{2}{*}{$\begin{array}{l}\text { Looking at the } \\
\text { map }\end{array}$} & All participants & $23 \%$ & $28 \%$ & $26 \%$ & $24 \%$ & $100 \%$ \\
\hline & & $\%$ within the group & $41 \%$ & $38 \%$ & $40 \%$ & $38 \%$ & $157 \%$ \\
\hline \multirow{2}{*}{ BUW } & \multirow{2}{*}{$\begin{array}{l}\text { Looking up and } \\
\text { down }\end{array}$} & All participants & $21 \%$ & $26 \%$ & $25 \%$ & $28 \%$ & $100 \%$ \\
\hline & & $\%$ within the group & $6 \%$ & $5 \%$ & $6 \%$ & $7 \%$ & $24 \%$ \\
\hline \multirow{2}{*}{$\mathrm{BRM}$} & \multirow{2}{*}{ Spinning the map } & All participants & $21 \%$ & $22 \%$ & $30 \%$ & $28 \%$ & $100 \%$ \\
\hline & & $\%$ within the group & $11 \%$ & $9 \%$ & $13 \%$ & $13 \%$ & $45 \%$ \\
\hline \multirow{2}{*}{$\mathrm{BN}$} & \multirow{2}{*}{$\begin{array}{l}\text { Confirming the } \\
\text { current location }\end{array}$} & All participants & $22 \%$ & $26 \%$ & $24 \%$ & $29 \%$ & $100 \%$ \\
\hline & & $\%$ within the group & $9 \%$ & $8 \%$ & $8 \%$ & $10 \%$ & $35 \%$ \\
\hline \multirow{2}{*}{$\mathrm{BR}$} & \multirow{2}{*}{ Spinning the body } & All participants & $18 \%$ & $33 \%$ & $25 \%$ & $24 \%$ & $100 \%$ \\
\hline & & $\%$ within the group & $4 \%$ & $5 \%$ & $4 \%$ & $4 \%$ & $17 \%$ \\
\hline \multirow{2}{*}{ BL } & \multirow{2}{*}{ Becoming lost } & All participants & $33 \%$ & $33 \%$ & $25 \%$ & $8 \%$ & $100 \%$ \\
\hline & & $\%$ within the group & $1 \%$ & $1 \%$ & $0 \%$ & $0 \%$ & $2 \%$ \\
\hline \multirow{2}{*}{$\mathrm{BM}$} & \multirow{2}{*}{ Keeping track } & All participants & $11 \%$ & $47 \%$ & $20 \%$ & $22 \%$ & $100 \%$ \\
\hline & & $\%$ within the group & $2 \%$ & $6 \%$ & $3 \%$ & $3 \%$ & $14 \%$ \\
\hline \multirow[t]{2}{*}{ total } & & $\begin{array}{l}\text { All wayfinding } \\
\text { performances }\end{array}$ & $22 \%$ & $32 \%$ & $25 \%$ & $21 \%$ & $100 \%$ \\
\hline & & $\%$ within the group & $100 \%$ & $100 \%$ & $100 \%$ & $100 \%$ & $400 \%$ \\
\hline
\end{tabular}

Two-way analysis of variance indicated that during wayfinding tasks, the interaction between lines and transparency in maps was significantly correlated with the number of times the participants expressed confusion and hesitation $(p=0.0421)$. Group B had the highest frequency of confusion and hesitation, followed by group C. Group D had the least confusion and hesitation. The locations where participants were confused and hesitant or lost were marked. In Table 12, black lines represent all the routes taken by participants within a group. Orange markers indicate locations where the participants were confused and hesitant, and red markers represent the segments where participants became lost.

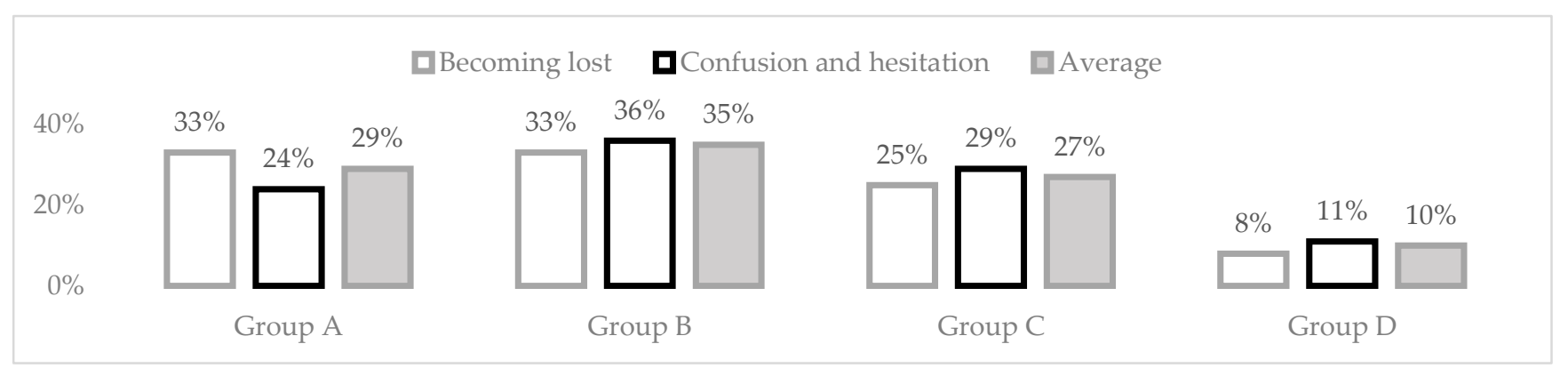

Figure 8. Frequency of ineffective wayfinding performances of each group in experiment two. 
Table 12. Routes taken in experiment two, and locations where BC or BL occurred.

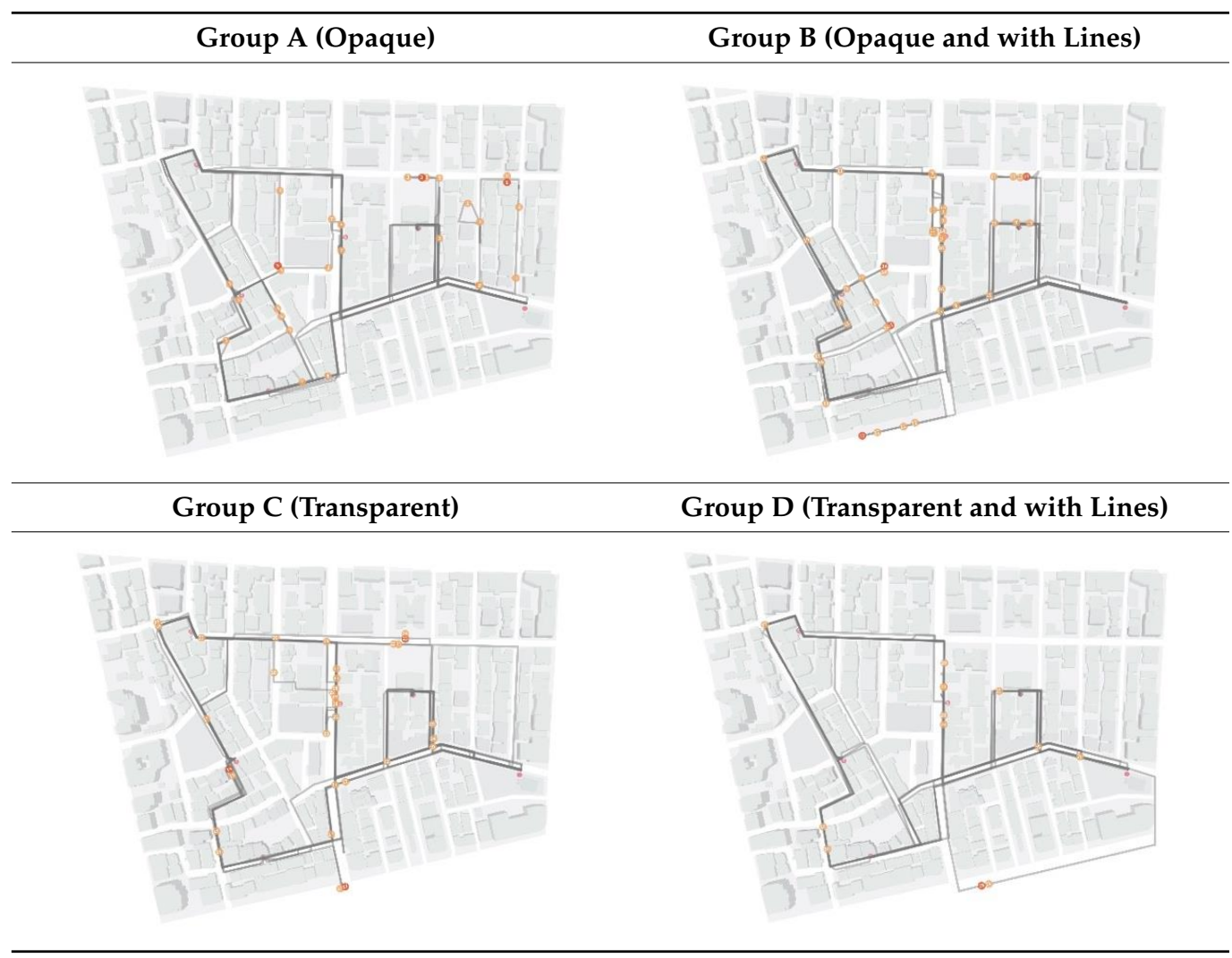

Routes taken by groups A and B were irrational, and both groups doubled back or overran more often than groups $C$ and D. Most participants overran because they missed intersections where they were supposed to turn. They usually used buildings, intersections, or main roads to identify their relative position and return to their original route. Group $\mathrm{D}$, who achieved a great consistency between the taken and planned routes, mentioned that buildings with lines helped them orientate. The consistency between the taken and planned routes showed Group D performed best at $88 \%$, followed by groups $\mathrm{C}, \mathrm{A}$, and B at $79 \%, 77 \%$, and $71 \%$, respectively.

\subsubsection{Orientation}

The average percentage difference between objective direction values (ODV) and cognitive direction estimates (CDE) is represented by the absolute accuracy score (AAS), as shown as below [39]. Differences between ODV and CDE greater than 180 are made smaller.

$$
\mathrm{AAS}=\left[\sum_{i=1}^{n}\left(\frac{\mathrm{ODV}-\mathrm{CDE}}{180}\right) \times 100\right] \div n
$$

The average AAS of the participants of groups A, B, C, and D was 26.6, 26.8, 24.5, and 21.7, respectively (Table 13). Compared with opaque maps, transparent maps enabled more accurate orientation. In addition, relative to maps without lines, maps with lines enabled more accurate orientation. With opaque maps, the cognitive maps of participants were incomplete because their line of sight was obstructed by opaque buildings. Therefore, these map users had to recall the route used for wayfinding during orientation and reorientate their bearings to identify the location of the mission marker. By contrast, when transparent maps were used, roads were less obstructed, resulting in map users having more comprehensive cognitive maps. 
Table 13. AAS of groups in experiment two.

\begin{tabular}{|c|c|c|c|c|c|c|}
\hline Task & $\begin{array}{l}\text { Recognition } \\
\text { Points }\end{array}$ & $\begin{array}{c}\text { Group A } \\
\text { (Opaque) }\end{array}$ & $\begin{array}{c}\text { Group B } \\
\text { (Opaque with } \\
\text { Lines) }\end{array}$ & $\begin{array}{c}\text { Group C } \\
\text { (Transparent) }\end{array}$ & $\begin{array}{c}\text { Group D } \\
\text { (Transparent with } \\
\text { Lines) }\end{array}$ & Average AAS \\
\hline 1 & start & 22.7 & 9.4 & 5.5 & 3.1 & 10.2 \\
\hline \multirow{2}{*}{2} & start & 8.6 & 25.0 & 14.8 & 32.8 & 20.3 \\
\hline & 1 & 11.7 & 27.3 & 14.1 & 33.6 & 21.7 \\
\hline \multirow{2}{*}{3} & start & 44.5 & 71.9 & 54.7 & 39.1 & 52.5 \\
\hline & 2 & 49.2 & 62.5 & 82.0 & 46.9 & 60.2 \\
\hline \multirow{2}{*}{4} & start & 29.7 & 27.3 & 25.0 & 15.6 & 24.4 \\
\hline & 3 & 40.6 & 8.6 & 22.7 & 18.0 & 22.5 \\
\hline \multirow{2}{*}{5} & start & 33.6 & 10.2 & 7.0 & 3.9 & 13.7 \\
\hline & 4 & 19.5 & 7.8 & 8.6 & 12.5 & 12.1 \\
\hline end & 5 & 6.3 & 18.0 & 10.2 & 11.7 & 11.5 \\
\hline \multicolumn{2}{|c|}{ Average AAS } & 26.6 & 26.8 & 24.5 & 21.7 & 24.9 \\
\hline
\end{tabular}

\subsubsection{Map Preference}

Regardless of the map each of them used, the participants were asked to rank the four map designs. Most preferred group D's map, followed by the maps of group C, group $\mathrm{B}$, and group A (Table 14). This result is similar to the reported findings. Participants who used a transparent map with lines (group D's map) used relative position (WD-6) along with mission markers or landmarks (WD-2) most often. When group D participants described buildings during map reading, they generally used landmarks for planning. These participants also had the highest consistency between the taken and planned route, required the least amount of time in planning, had the lowest frequency confusion and hesitation, and had the lowest orientation error rate.

Group A and group B participants generally used intersections to determine their current location during wayfinding, with buildings and landmarks as supporting references. Group C and group D participants reported that they only needed to know the surroundings of the destination to perform wayfinding. Therefore, their map did not need to present all the buildings; irrelevant buildings can be more transparent. Group B and group D participants mentioned that lines marking key landmarks assisted their orientation.

Table 14. Map preference after experiment two.

\begin{tabular}{cccccc}
\hline & Group A & Group B & Group C & Group D & Percentage \\
\hline $\mathrm{B}>\mathrm{A}>\mathrm{D}>\mathrm{C}$ & 3 & 1 & 0 & 0 & $13 \%$ \\
\hline $\mathrm{B}>\mathrm{D}>\mathrm{A}>\mathrm{C}$ & 1 & 0 & 0 & 0 & $3 \%$ \\
\hline $\mathrm{C}>\mathrm{D}>\mathrm{A}>\mathrm{B}$ & 1 & 1 & 0 & 0 & $6 \%$ \\
\hline $\mathrm{C}>\mathrm{D}>\mathrm{B}>\mathrm{A}$ & 1 & 0 & 2 & 0 & $9 \%$ \\
\hline $\mathrm{D}>\mathrm{B}>\mathrm{A}>\mathrm{C}$ & 0 & 0 & 0 & 2 & $6 \%$ \\
\hline $\mathrm{D}>\mathrm{B}>\mathrm{C}>\mathrm{A}$ & 1 & 2 & 0 & 2 & $16 \%$ \\
\hline $\mathrm{D}>\mathrm{C}>\mathrm{A}>\mathrm{B}$ & 0 & 0 & 2 & 1 & $9 \%$ \\
\hline $\mathrm{D}>\mathrm{C}>\mathrm{B}>\mathrm{A}$ & 1 & 4 & 4 & 3 & $38 \%$ \\
\hline total & 8 & 8 & 8 & 8 & $100 \%$ \\
\hline
\end{tabular}

\section{Discussion}

From the results of the first experiment, we understood that during wayfinding, the view angle and building density of maps affected the spatial cognition and wayfinding 
strategies of the participants. The experiment involved the use of high- and low-density maps. Compared with high-density maps, low-density maps enabled superior wayfinding performance. The purpose of wayfinding maps is to provide information for determining direction. According to Apelt [40], map designs should present the surrounding environment in a clear space that is noticeable and easy to read such that map users can interpret the information in their own language. High-density maps presented all the buildings; therefore, the users required time to transform spaces into memory. In addition, buildings in high-density maps obstructed roads, resulting in users exhibiting confusion and hesitation or becoming lost. Therefore, most participants stated that highlighting landmarks near the destination assisted them in map reading.

Of the $30^{\circ}, 60^{\circ}$, and $90^{\circ}$ maps, maps with higher view angles allowed superior simulated wayfinding performance. In addition, perspective maps enabled superior performance relative to planimetric maps. The participants indicated that the $30^{\circ}$ maps had an excellent first-person view angle, but distant buildings appeared smaller and harder to read. The participants also indicated that $60^{\circ}$ and $90^{\circ}$ maps provided perspective and wider vision, and buildings did not obstruct roads, thereby allowing them to locate their position and orientation space. High view angles can highlight elements and features of maps and improve wayfinding performance.

Low-density maps enable superior wayfinding performance; however, urban environments contain tall buildings, and high-density maps are the norm. Therefore, the second experiment explored designs of high-density maps that were easy to understand. To overcome the problem of obstruction (often present in high-density maps), we added the two design variables of transparency and lines, and explored how different map designs affected wayfinding performance and cognition. The results suggest that including adequate transparency and lines in map designs can improve the wayfinding performance of map users.

Table 15 contains 11 comment topics and relationships among the map designs after cross-analysis ( ${ }^{*}$ signifies $p<0.05$ ). Our findings are as follows.

- Buildings in group A and group B maps are opaque: The participants felt that the transparency used in group B maps increased the complexity of wayfinding $(p=0.015<0.05)$. They indicated that they had to spend time observing the border between buildings and roads, and that lines made the map "messy" and hard to read.

- Buildings in group C and group D maps are transparent: The participants felt that group D maps, which included lines, were easier to understand $(p=0.031<0.05)$ and use $(p=0.016<0.05)$. They mentioned that lines emphasized key landmarks and made the maps easier to understand and use.

- Buildings in group A maps and group C maps do not include lines: The participants felt that group A maps, which were opaque, were easier to understand $(p=0.016<0.05)$ and use $(p=0.021<0.05)$, whereas the transparency in group $C$ maps facilitated identification of landmarks $(p=0.018<0.05)$. Transparency can make irrelevant buildings fainter, and drawing all nearby buildings is not necessary. However, this could result in the map losing focus and its users becoming lost in the map.

- When lines were included into group B and group D maps, the two groups did not exhibit any significant difference. Lines can help map users use key landmarks to locate their position. Transparency can create a sense of layers in a map. After key areas are marked, other areas can be made semi-transparent to reduce obstruction while maintaining crucial information. However, if the map is too transparent, the complementary landmark information is difficult to read.

Table 16 ranks route planning performance, wayfinding performance, and the evaluation of maps in experiment two. Because the comparison items had positive and negative questions, maps were ranked by assigning 4 points to the map with the most favorable performance, with the next-best maps assigned 3, 2, and 1 point accordingly. According to the results, group D's map had the most favorable performance, followed by maps of group A, group C, and group B. 
Table 15. Comments on and cross-analysis of map designs. $\left({ }^{*} p<0.05\right)$.

\begin{tabular}{|c|c|c|c|c|c|}
\hline No. & Topic & $\begin{array}{c}\text { Group A } \\
\text { (Opaque) } \\
\text { and } \\
\text { Group B } \\
\text { (Opaque with } \\
\text { Lines) }\end{array}$ & $\begin{array}{c}\text { Group C } \\
\text { (Transparent) } \\
\text { and } \\
\text { Group D } \\
\text { (Transparent with } \\
\text { Lines) }\end{array}$ & $\begin{array}{c}\text { Group A } \\
\text { (Opaque) } \\
\text { and } \\
\text { Group C } \\
\text { (Transparent) }\end{array}$ & $\begin{array}{c}\text { Group B } \\
\text { (Opaque with Lines) } \\
\text { and } \\
\text { Group D } \\
\text { (Transparent with } \\
\text { Lines) }\end{array}$ \\
\hline 1 & $\begin{array}{l}\text { I prefer planimetric maps over } \\
\text { the experiment maps }\end{array}$ & 1.000 & 0.512 & 0.287 & 0.387 \\
\hline 2 & $\begin{array}{l}\text { I think that the experiment } \\
\text { maps were useful for } \\
\text { orientation }\end{array}$ & 0.657 & 0.334 & 0.246 & 0.278 \\
\hline 3 & $\begin{array}{l}\text { I think that the experiment } \\
\text { maps were easy to understand }\end{array}$ & 0.582 & 0.031 * & $0.016^{*}$ & 0.875 \\
\hline 4 & $\begin{array}{l}\text { I think that the experiment } \\
\text { maps facilitate wayfinding }\end{array}$ & 0.306 & 0.219 & 0.116 & 0.849 \\
\hline 5 & $\begin{array}{l}\text { I think that the overall layout } \\
\text { of this map is crowded }\end{array}$ & 0.256 & 0.268 & 0.082 & 0.590 \\
\hline 6 & $\begin{array}{l}\text { I think that the buildings on } \\
\text { the map increased the } \\
\text { complexity of wayfinding }\end{array}$ & 0.678 & 0.387 & 0.678 & 0.387 \\
\hline 7 & $\begin{array}{l}\text { I think that the buildings on } \\
\text { this map were useful for } \\
\text { orientation }\end{array}$ & 0.849 & 0.512 & 0.152 & 0.126 \\
\hline 8 & $\begin{array}{l}\text { I think that the transparency } \\
\text { in this map increased the } \\
\text { complexity of wayfinding }\end{array}$ & 0.015 * & 0.758 & 0.577 & 0.063 \\
\hline 9 & $\begin{array}{l}\text { I think that the transparency } \\
\text { in this map enabled easier } \\
\text { identification of landmarks }\end{array}$ & 0.167 & 0.140 & 0.018 * & 0.876 \\
\hline 10 & $\begin{array}{l}\text { I think that this map is easy to } \\
\text { use }\end{array}$ & 0.362 & $0.016^{*}$ & 0.021 * & 0.349 \\
\hline 11 & $\begin{array}{l}\text { I think that spatial } \\
\text { transformation between this } \\
\text { map and the actual } \\
\text { environment is easy }\end{array}$ & 0.908 & 0.219 & 0.082 & 0.066 \\
\hline
\end{tabular}

Table 16. Mixed comparison of the groups in experiment two.

\begin{tabular}{|c|c|c|}
\hline Comparison Item & Ranking & Value \\
\hline $\begin{array}{l}\text { Expressions of confusion and hesitation during route } \\
\text { planning }\end{array}$ & $\mathrm{B}>\mathrm{A}>\mathrm{C}=\mathrm{D}$ & $38 \%>31 \%>15 \%=15 \%$ \\
\hline Wayfinding time & $\mathrm{C}>\mathrm{B}>\mathrm{A}>\mathrm{D}$ & $25: 58>24: 57>23: 31>21: 38$ \\
\hline $\begin{array}{l}\text { Average frequency of ineffective wayfinding behavior: } \\
\text { confusion/hesitation and becoming lost }\end{array}$ & $\mathrm{B}>\mathrm{A}>\mathrm{C}>\mathrm{D}$ & $36 \%>29 \%>27 \%>10 \%$ \\
\hline AAS & $\mathrm{B}>\mathrm{A}>\mathrm{C}>\mathrm{D}$ & $26.8>26.6>24.5>21.7$ \\
\hline Cognitive map: intersection errors & $\mathrm{C}>\mathrm{A}>\mathrm{B}=\mathrm{D}$ & $15>11>3=3$ \\
\hline Consistency between the taken and planned route & $\mathrm{D}>\mathrm{C}>\mathrm{A}>\mathrm{B}$ & $88 \%>79 \%>77 \%>71 \%$ \\
\hline Consistency between taken route and cognitive map & $\mathrm{A}>\mathrm{D}>\mathrm{B}>\mathrm{C}$ & $92 \%>90 \%>88 \%>83 \%$ \\
\hline Evaluation after map use & $\mathrm{D}>\mathrm{A}>\mathrm{C}>\mathrm{B}$ & $42>34>25>19$ \\
\hline
\end{tabular}


The first experiment indicated that maps do not have to present every building, and only key landmarks need be presented during wayfinding. The wayfinding performance of map users was improved by including transparency and lines in maps. Therefore, in map design, the following should be considered. First, buildings and landmarks in 2.5D maps should have adequate transparency and lines to improve map reading and help users recall map features. Second, highlighting landmarks at intersections, such as by emphasizing building features, can enable map users to use an intersection as a reference when making a turn. Finally, high view angle and high-density maps should present landmarks differently to prioritize specific landmarks.

\section{Conclusions}

We found that the groups using high-density maps required more time than whereas groups that used low-density maps. The difference was significant. The results for three of the four tasks also indicated that the interaction between view angle and density was significantly correlated with the frequency of participants expressing confusion.

The 2.5D maps use perspective drawing to add depth and help map users orientate. Perspective maps enable wayfinding performance superior to that with planimetric maps. Compared with users of low view angle maps, those using high view angle maps orientated more easily with elements of the map during wayfinding tasks. The most common wayfinding strategy of participants was to remember the number of left and right turns and specific intersections. Participants were most commonly confused at turning points of intersections, and they often doubled back to familiar location points. Therefore, a 2.5D map design should put consideration into intersections and mark key landmarks for increased recognition. Reading planimetric maps usually relies on intuition, whereas 2.5D maps can use environmental features to improve the recollection of map users and locating of features in the remapping process. Therefore, $2.5 \mathrm{D}$ maps are suitable for users with lower spatial ability, as these maps can improve the wayfinding performance of these users. When 2.5D maps are drawn with first-person view angles, the visual perceptions of map users are more similar to the reality. However, view angle tilting should produce views containing more information. If the map has a low view angle, problems such as obstruction can occur, whereas a map with a high view angle can increase dimensionality, emphasize map elements, and thus help users locate their destination and improve wayfinding performance. In short, the principle in setting the view angle of maps is not to obstruct roads. In this study, low-density maps enabled superior performance. In addition, high view angle maps allowed superior performance, and including transparency and lines improved wayfinding performance. The participants using maps that were opaque and with lines exhibited the most confusion and hesitation, followed by the participants using maps that were transparent and without lines. The participants who used maps that were transparent and had lines exhibited the least confusion and hesitation.

Adding transparency and lines to a map can create a sense of layers; however, excessive lines and transparency when presenting buildings may make the map messy, with users unable to locate the destination and its relationship with the surrounding environment. Furthermore, during the wayfinding experiment, map users were often confused and hesitant at intersections. The second experiment emphasized landmarks at intersections to reduce confusion and hesitation. Therefore, highlighting buildings at intersections can help map users use the intersections as references and increase their intuitive spatial recognition ability.

Author Contributions: M.-C.Z. contributed to the original ideas of the paper and designed the experiments. Y.-W.H. performed the experiments and analyzed the experimental data under the supervision of M.-C.Z. Y.-W.H. wrote the first draft of the manuscript; M.-C.Z. revised and edited it. All authors have read and agreed to the published version of the manuscript.

Funding: This research received no external funding.

Institutional Review Board Statement: Not applicable. 
Informed Consent Statement: Not applicable.

Data Availability Statement: Due to confidentiality agreements, supporting data can only be made available to bona fide researchers subject to a non-disclosure agreement. Details of the data and how to request access are available from M.-C.Z. (zmcdesign@gmail.com) at National Taipei University of Technology.

Acknowledgments: Special thanks for all participants who generously shared their time and experience, for the purposes of this study sections.

Conflicts of Interest: The authors declare no conflict of interest.

\section{References}

1. Tolman, E.C. Cognitive maps in rats and men. Psychol. Rev. 1948, 55, 189-208. [CrossRef]

2. Tversky, B. Structures of Mental Spaces: How People Think About Space. Environ. Behav. 2003, 35, 66-80. [CrossRef]

3. Robinson, A.H.; Petchenik, B.B. The Nature of Maps: Essays toward Understanding Maps and Mapping; University of Chicago Press: Chicago, IL, USA, 1976.

4. Ottosson, T. Map-Reading and Wayfinding; Acta Universitatis Gothoburgensis: Göteborg, Sweden, 1987.

5. Maceachren, A. How Maps Work: Representation, Visualization and Design; Distributed by Longman outside N.; Guilford Press: New York, NY, USA, 1995.

6. Caduff, D.; Timpf, S. A framework for assessing the salience of landmarks for wayfinding tasks. Cogn. Process. 2006, 7, 23. [CrossRef]

7. O'Neill, M. Effects of signage and floor plan configuration on wayfinding accuracy. Environ. Behav. 1991, 23, 553-574. [CrossRef]

8. Tom, A.; Denis, M. Referring to landmark or street information in route directions: What difference does it make? In Spatial Information Theory. Foundations of Geographic Information Science; Kuhn, W., Worboys, M.F., Timpf, S., Eds.; COSIT 2003, Lecture Notes in Computer Science; Springer: Berlin/Heidelberg, Germany, 2003; Volume 2825, pp. 362-374.

9. Burnett, G.; Smith, D.; May, A. Supporting the navigation task: Characteristics of "good" landmarks. In Proceedings of the Annual Conference of the Ergonomics Society, Turin, Italy, 7-9 November 2001.

10. Martin, R.; Winter, S. Enriching Wayfinding Instructions with Local Landmarks; Springer: Berlin/Heidelberg, Germany, 2002; pp. 243-259.

11. Denis, M.; Pazzaglia, F.; Cornoldi, C.; Bertolo, L. Spatial discourse and navigation: An analysis of route directions in the city of Venice. Appl. Cogn. Psychol. 1999, 13, 145-174. [CrossRef]

12. Moeser, S.D. Cognitive Mapping in a Complex Building. Environ. Behav. 1988, 20, 21-49. [CrossRef]

13. Kitchin, R.; Blades, M. The Cognition of Geographic Space; I.B. Tauris: London, UK, 2002.

14. Casakin, H.; Barkowsky, T.; Kpippel, A.; Freksa, C. Schematic maps as wayfinding aids. In Spatial Cognition II: Integrating Abstract Theories, Empirical Studies, Formal Methods, and Practical Applications; Freksa, C., Brauer, W., Habel, C., Wender, K.F., Eds.; Springer: Berlin/Heidelberg, Germany, 2000; pp. 54-71.

15. Golledge, R.G. Wayfinding Behavior: Cognitive Mapping and Other Spatial Processes; Johns Hopkins University Press: Baltimore, MD, USA, 1999.

16. Seneviratne, P.N.; Morerall, J.F. Level of service on pedestrian facilities. Transp. Q. 1985, 39, 109-123.

17. Ueberschaer, M.H. Choice of routes on urban networks for the journey to work. Highw. Res. Rec. 1971, 369, 228-238.

18. Ito, K.; Sano, Y. Cultural Differences in the Use of Spatial Information in Wayfinding Behavior. In Proceedings of the 25th International Cartographic Conference, Paris, France, 3-8 July 2011.

19. Koláčný, A. Cartographic information-A fundamental concept and term in modern cartography. Cartogr. J. 1977, 14, 39-45. [CrossRef]

20. Van Elzakker, C.P. The Use of Maps in the Exploration of Geographic Data; Koninklijk Nederlands Aardrijkskundig Genootschap: Utrecht, The Netherlands, 2004; p. 19.

21. Fujimori, F.; Arikawa, M.; Morita, T. Extraction of spatial relations on SVG maps and its applications. In Proceedings of the IEICE DEWS, Kaga, Japan, 3-5 March 2003.

22. Bertin, J. Semiology of Graphics: Diagrams, Networks, Maps; ESRI Press: Redlands, CA, USA, 2010.

23. Tang, C.; Lin, C.; Hsu, Y. Exploratory research on reading cognition and escape-route planning using building evacuation plan diagrams. Appl. Ergon. 2008, 39, 209-217. [CrossRef] [PubMed]

24. Lee, J.; Olwal, A.; Ishii, H.; Boulanger, C. SpaceTop: Integrating 2D and spatial 3D interactions in a see-through desktop environment. In Proceedings of the SIGCHI Conference on Human Factors in Computing Systems, Paris, France, 27 April-2 May 2013; pp. 189-192.

25. Sweany, J.B. Cognitive Demand of Engineering Information. Ph.D. Thesis, University of Colorado at Boulder, Boulder, CO, USA, 2014.

26. Blair, J.P.; Schweit, K. A Study of Active Shooter Incidents, 2000-2013; Texas State University and Federal Bureau of Investigation; US Department of Justice: Washington, DC, USA, 2014.

27. Blair, J.P.; Nichols, T.; Burns, D.; Curnutt, J.R. Active Shooter Events and Response; CRC Press: Washington, DC, USA, 2013. 
28. Teizer, J.; Cheng, T.; Fang, Y. Location tracking and data visualization technology to advance construction ironworkers' education and training in safety and productivity. Autom. Constr. 2013, 35, 53-68. [CrossRef]

29. Zheng, M.C. Influences of different underground station map designs on map-reading and wayfinding. Geoinformatica 2020, 24, 531-555. [CrossRef]

30. Passini, R. Wayfinding in Architecture; Van Nostrand Reinhold: New York, NY, USA, 1984; Volume 4.

31. You, M.-L.; Chen, C.-W.; Lee, P.-J. Effects of Map View and Landmark Presentation Styles on Usability of Wayfinding Maps. J. Des. 2006, 11, 85-99.

32. Marr, D.; Vision, A. A Computational Investigation into the Human Representation and Processing of Visual Information; Freeman and Company: San Francisco, CA, USA, 1982.

33. Kealy, W.A. Map perspective and the learning of text. Contemp. Educ. Psychol. 1995, 20, 457-463.

34. Kiefer, P.; Giannopoulos, I.; Raubal, M. Where Am I? Investigating Map Matching during Self- Localization with Mobile Eye Tracking in an Urban Environment. Trans. GIS 2014, 18, 660-686. [CrossRef]

35. Limberger, D.; Scheibel, W.; Trapp, M.; Döllner, J. Mixed-projection treemaps: A novel approach mixing $2 \mathrm{~d}$ and $2.5 \mathrm{~d}$ treemaps. In Proceedings of the 2017 21st International Conference Information Visualisation (IV), London, UK, 11-14 July 2017; IEEE: Piscataway, NJ, USA, 2017; pp. 164-169.

36. Zanola, S.; Fabrikant, S.I.; Çöltekin, A. The Effect of Realism on the Confidence in Spatial Data Quality in Stereoscopic 3D Displays. In Proceedings of the 24th International Cartography Conference (ICC 2009), Santiago, Chile, 15-21 November 2009; pp. $15-21$.

37. Liao, H.; Dong, W.; Peng, C.; Liu, H. Exploring differences of visual attention in pedestrian navigation when using 2D maps and 3D geo-browsers. Cartogr. Geogr. Inf. Sci. 2017, 44, 474-490. [CrossRef]

38. Xia, N.K.; Tian, P.J. Detailed Control Planning; Tongji University Press: Shanghai, China, 2005.

39. Kitchin, R.M.; Jacobson, R.D. Techniques to collect and analyze the cognitive map knowledge of persons with visual impairment or blindness: Issues of validity. J. Vis. Impair. Blind. 1997, 91, 360-376. [CrossRef]

40. Apelt, R. Wayfinding in the Built Environment; Tech. Rep.; Public Works Queensland: Brisbane, QLD, Australia, 2008. 